JULIANA CHRISTIANO DE MATOS VINAGRE

\title{
Efeitos da dieta vegetariana no metabolismo de quilomícrons e aspectos qualitativos da lipoproteína de alta densidade (HDL)
}

Tese apresentada à Faculdade de Medicina da Universidade de São Paulo para obtenção do título de Doutor em Ciências

Programa de: Cardiologia

Orientador: Prof. Dr. Raul Cavalcante Maranhão 
JULIANA CHRISTIANO DE MATOS VINAGRE

\section{Efeitos da dieta vegetariana no metabolismo de quilomícrons e aspectos qualitativos da lipoproteína de alta densidade (HDL)}

Tese apresentada à Faculdade de Medicina da Universidade de São Paulo para obtenção do título de Doutor em Ciências

Programa de: Cardiologia

Orientador: Prof. Dr. Raul Cavalcante Maranhão 
Dados Internacionais de Catalogação na Publicação (CIP)

Preparada pela Biblioteca da

Faculdade de Medicina da Universidade de São Paulo

Creprodução autorizada pelo autor

Vinagre, Juliana Christiano de Matos

Efeitos da dieta vegetariana no metabolismo de quilomícrons e aspectos qualitativos da lipoproteína de alta densidade (HDL) / Juliana Christiano de Matos Vinagre. -- São Paulo, 2010.

Tese(doutorado)--Faculdade de Medicina da

Universidade de São Paulo.

Programa de Cardiologia.

Orientador: Raul Cavalcante Maranhão.

Descritores: 1.Lipídeos 2.Lipoproteínas 3.Quilomícrons 4.Remanescentes

de quilomícrons 5.Dieta vegetariana 6.Aterosclerose 
Dedicatória

A minha querida avó Cléo, in memorium,

por todo carinho, amor e incentivo. 


\section{Agradecimentos}

Ao meu orientador, Prof. Raul Cavalcante Maranhão, pela oportunidade e apoio na minha formação científica com seu exemplo profissional.

A minha mãe, pela pessoa maravilhosa que é e em quem eu me espelho todos os dias. Obrigada por tudo que fez e faz todos os dias por mim. Te amo!

Ao meu querido pai, que mesmo mais distante, sempre me apoiou e acreditou em mim durante todos esses anos.

Ao meu irmão e a minha cunhada Teresa, por todos os momentos felizes que me fizeram passar ao longo desses anos e principalmente por iluminarem nossa família com essas pessoinhas mais lindas do mundo: Babi e Pedro.

Ao Bill pelo carinho, e pela ajuda sempre que precisei, principalmente no inglês.

Ao Guto, por todo amor e carinho durante todos esses anos. Obrigada pela compreensão e paciência, principalmente nos momentos finais da conclusão dessa tese

A minha amiga Fernanda Pozzi por toda ajuda no desenvolvimento desse trabalho, amizade, compreensão e todos os momentos de descontração e alegria.

A Nany Aptekmann, por ter se tornado uma grande amiga. Obrigada por todo carinho, companhia e disponibilidade em me ajudar sempre.

A Mariana Albertini, a nova geração do laboratório, pela disponibilidade e boa vontade de sempre.

A minha querida prima Adriana, por todos os momentos de alegrias e risadas e por me suportar e me confortar nos momentos que mais precisei.

A Rosane Stefani por todo auxílio e disposição em ajudar-me na realização desta tese.

A querida Débora Deus e ao Wanderlei, por toda paciência e ajuda nas coletas.

Agradeço a todos do laboratório de Metabolismo de Lípides por me apoiarem e me auxiliarem durantes esses anos. 


\section{Sumário}

\section{Lista de abreviaturas}

Lista de figuras

Lista de tabelas

Resumo

Abstract

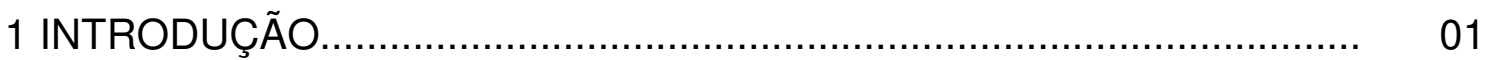

1.1 Dieta vegetariana

1.2 Metabolismo de lípides e dieta vegetariana......................................... 06

1.3 Metabolismo da Lipoproteína de Alta Densidade (HDL) ....................... 07

1.4 Metabolismo de Quilomícrons............................................................. 10

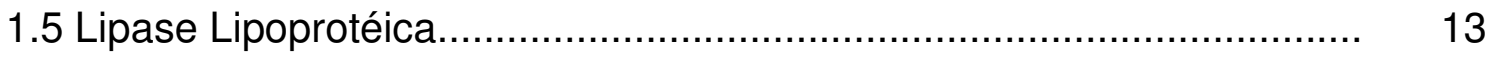

1.6 Metabolismo de Quilomícrons e Aterosclerose.................................... 14

1.7 Metodologias para Avaliação do Metabolismo de Quilomícrons............ 17

2 OBJETIVOS

2.1 Objetivos gerais......................................................... 22

2.2 Objetivos específicos................................................... 22

3.0 CASUÍSTICA, MATERIAL E MÉTODOS................................ 24

4.1 Casuística................................................................... 25

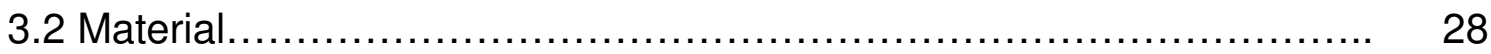

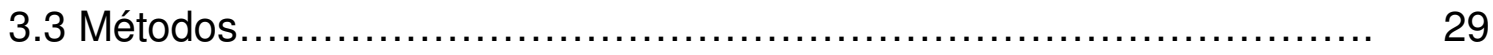

3.3.1 Preparo da emulsão de quilomícrons artificiais.............................. 29

3.3.2.Preparo da nanoemulsão semelhante à LDL

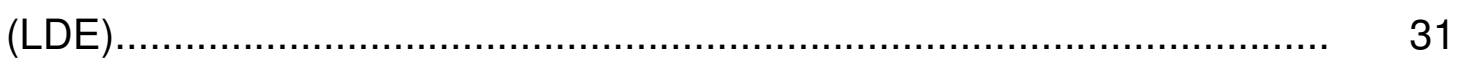

3.3.3 Estudos cinéticos com a emulsão de quilomícrons articiais............ 32

3.3.4 Ausência de risco relacionada aos estudos cinéticos...................... 33

3.3.5 Análise dos dados cinéticos..................................................... $\quad 35$

3.3.6Análise da cinética do éster de colesterol marcado com ${ }^{14} \mathrm{C}\left(\mathrm{EC}-{ }^{14} \mathrm{C}\right) \quad 37$

3.3.7 Análise cinética dos triglicérides marcados $\operatorname{com}^{3} \mathrm{H}\left(\mathrm{TG}-{ }^{3} \mathrm{H}\right) \ldots \ldots \ldots \ldots . \quad 38$

3.3.8 Atividade da lípase lipoprotéica (LLP)......................................... 39 
3.3.9 Determinações bioquímicas.

3.3.10 Avaliação da "Transferência de Lípides da Nanoemulsão LDE para a HDL"

3.3.11 Determinação do Diâmetro da HDL............................................. 43

4.3.12 Análise estatística.

4. RESULTADOS.

4.1 Características clínicas dos grupos estudados.

4.2 Estimativa de ingestão de energia e macronutrientes entre veganos, ovolacto-vegetarianos e onívoros.

4.3 Taxa fracional de remoção do éster de colesterol (TFR-EC- ${ }^{14} \mathrm{C}$ ) e dos triglicérides (TFR-TG ${ }^{3} \mathrm{H}$ ), taxa de lipólise e atividade da lipase lipoprotéica

4.4 Determinações bioquímicas.

4.5 Taxa de transferência de éster de colesterol, colesterol, triglicérides e fosfolípides da LDE para a HDL e diâmetro da HDL.

4.6 Correlações entre taxa fracional de éster de colesterol (TFR-EC- ${ }^{14} \mathrm{C}$ ) e o consumo de carboidratos, proteínas, gordura saturada, fibras e colesterol

5. DISCUSSÃO.

6. CONCLUSÕES.

\section{ANEXOS}




\section{LISTA DE ABREVIATURAS}

\begin{tabular}{|c|c|}
\hline ABCA-1 & "ATP-binding cassete transporters A1" \\
\hline ACAT & acil-colesterol-acil transferase \\
\hline AF & atividade física \\
\hline APO & apolipoproteína, como apo A1, apo B100, apo E \\
\hline CE & colesterol esterificado ou éster de colesterol \\
\hline CETP & proteína de transferência do éster de colesterol \\
\hline CL & colesterol livre \\
\hline CT & colesterol total \\
\hline DAC & doença arterial coronária \\
\hline DP & desvio padrão \\
\hline DVC & doença cardiovascular \\
\hline $\mathbf{F L}$ & fosfolípides \\
\hline HDL & lipoproteína de alta densidade \\
\hline HDL-C & colesterol da lipoproteína de alta densidade \\
\hline IDL & lipoproteína de densidade intermediária \\
\hline IMC & índice de massa corpórea \\
\hline LCAT & lecitina-colesterol-acil transferase \\
\hline LDE & nanoemulsão artificial rica em colesterol \\
\hline
\end{tabular}


LDL lipoproteína de baixa densidade

LDL-C colesterol da lipoproteína de baixa densidade

LLP lipase lipoprotéica

LRP "LDL receptor related protein"

OLV ovolacto-vegetariano

ON onívoro

Qm quilomícron

Qm-r remanescente de quilomícron

SH sulfato de heparana

TFR taxa fracional de remoção

TG triglicérides

V vegano

VLDL lipoproteína de densidade muito baixa

VLDL-C colesterol da lipoproteína de densidade muito baixa 


\section{LISTA DE FIGURAS}

FIGURA 1. Modelo compartimental adotado para análise para de cinética plasmática dos quilomícrons artificiais.

FIGURA 2. Curvas de remoção plasmática do éster de colesterol- ${ }^{14} \mathrm{C}$ dos quilomícrons artificiais nos grupos vegano, ovolacto-vegetariano e onívoro 49

FIGURA 3. Curvas de remoção plasmática dos triglicérides $-{ }^{3} \mathrm{H}$ dos quilomícrons artificiais nos grupos vegano, ovolacto-vegetariano e onívoro. 50

FIGURA 4. Correlações entre taxa fracional de éster de colesterol (TFR-EC${ }^{14} \mathrm{C}$ ) e o consumo de carboidratos, proteínas, gordura saturada, fibras e colesterol .56 


\section{LISTA DE TABELAS}

TABELA 1. Características clínicas dos grupos vegano, ovolacto-vegetariano e onívoro. 46

TABELA 2. Estimativa de ingestão de energia e macronutrientes entre os grupos estudados. 48

TABELA 3. Taxa fracional de remoção do éster de colesterol (TFR-EC- ${ }^{14} \mathrm{C}$ ) e dos triglicérides (TFR-TG- ${ }^{3} \mathrm{H}$ ), em $\min ^{-1}$ e atividade da lipase lipoprotéica nos grupos estudados. 51

TABELA 4. Concentrações plasmáticas dos lipídeos e glicose dos grupos estudados. .52

TABELA 5. Taxa de transferência (\%) do éster de colesterol, colesterol livre, triglicerídeos e fosfollpídeos da emulsão rica em colesterol (LDE) para a HDL e diâmetro das partículas de HDL $(\mathrm{nm})$ nos grupos estudados. .53

TABELA 6. Correlação entre a taxa fracional de éster de colesterol e o consumo de calorias totais, carboidrato, proteína, gordura total, gordura saturada, gordura poliinsaturada, gordura monoinsaturada, fibras e colesterol. .55 


\section{RESUMO}

Vinagre JCM. Efeitos da dieta vegetariana no metabolismo de quilomícrons e aspectos qualitativos da lipoproteína de alta densidade (HDL). 2010. Tese (Doutorado) - Faculdade de Medicina da Universidade de São Paulo.

Dietas vegetarianas oferecem baixo conteúdo calórico, baixos níveis de gordura saturada, colesterol, proteína animal e mais altos de gordura polinsaturada, carboidratos, fibras, magnésio, boro, folato e antioxidantes. Todos esses nutrientes influenciam nos fatores de risco de doenças cardiovasculares como hipertensão arterial, diabetes mellitus, obesidade e dislipidemias. Níveis plasmáticos de colesterol total, colesterol de lipoproteína de baixa densidade (LDL), de lipoproteína de densidade muito baixa (VLDL) e triglicérides em indivíduos vegetarianos são menores, em vários estudos, quando comparados a indivíduos onívoros. O metabolismo de quilomícrons $(Q m)$ e dos seus produtos de degradação pela lipase lipoprotéica, os remanescentes, lipoproteínas que transportam os lípides da dieta na circulação sanguínea, não foi avaliado até o momento e está relacionado à aterosclerose. O objetivo deste estudo foi avaliar a cinética plasmática de quilomícrons artificiais marcados com triglicérides $\left(\mathrm{TG}-{ }^{3} \mathrm{H}\right)$ e éster de colesterol $\left(\mathrm{EC}-{ }^{14} \mathrm{C}\right)$ e aspectos qualitativos da $\mathrm{HDL}$, em 18 indivíduos ovolacto-vegetarianos (excluem da alimentação carne, frango e peixe), 21 indivíduos veganos (não consomem nenhum alimento de origem animal), há pelo menos 5 anos e 29 indivíduos onívoros (consomem alimentos de origem animal), todos normolipidêmicos, não diabéticos e sem uso de medicamentos hipolipemiantes. Após a injeção endovenosa dos Qm artificias, foram colhidas amostras de sangue em tempos pré-estabelecidos durante 60 minutos. A radioatividade em cada uma das amostras foi medida para o cálculo da taxa fracional de remoção (TFR) dos lípides radioativos, através de análise compartimental. Foram realizadas as determinações bioquímicas nesses indivíduos e calculada a atividade da lipase lipoprotéica pós-heparina, em ensaio in vitro. Verificou-se também a transferência de lípides de uma nanoemulsão lipídica para a lipoproteína de alta densidade (HDL) e o diâmetro dessa lipoproteína. A remoção plasmática dos remanescentes de quilomícrons avaliada pela taxa fracional de remoção do éster de colesterol da emulsão, foi maior nos veganos 
$(p<0,05)$ e ovolacto-vegetarianos $(p<0,05)$ comparando-se aos onívoros, enquanto que o processo de lipólise dos quilomícrons, avaliado pela taxa fracional de remoção dos triglicérides da emulsão e pela medida da atividade da lipase lipoprotéica in vitro foi similar nos três grupos avaliados. Não foram encontradas diferenças significativas nas concentrações plasmáticas de HDLC, VLDL e triglicérides entre os grupos estudados .No grupo vegano, as concentrações plasmáticas de LDL-C e glicose foram menores quando comparadas apenas ao grupo dos onívoros ( $\mathrm{p}<0,05, \mathrm{p}<0,01$; respectivamente). Já em relação ao colesterol total, os indivíduos veganos apresentaram menores níveis quando comparados tanto aos ovolacto-vegetarianos $(p<0,05)$ como aos onívoros $(p<0,01)$. Não observou-se diferença na transferência de lípides da nanoemulsão para a HDL e no tamanho da HDL entre os três grupos. Os resultados do presente estudo sugerem que a dieta vegana e ovolacto-vegetariana aceleram a remoção dos remanescentes de quilomícrons, lipoproteínas aterogênicas, o que pode estar relacionado, aos efeitos benéficos dessa dieta em relação a doenças em relação ao processo aterosclerótico.

Descritores: Lipídeos, lipoproteínas, quilomícrons, remanescentes de quilimícrons, dieta vegetariana e aterosclerose 


\section{ABSTRACT}

Vinagre JCM. Effects of vegetarian diets on chylomicron metabolism and high density lipoprotein qualitative aspects (HDL). 2010. Thesis (Doctoral) Faculdade de Medicina da Universidade de São Paulo.

Vegetarian diets provide less caloric content, low levels of saturated fats, cholesterol and animal protein while providing at the same time providing high levels of polyunsaturated fats, carbohydrates, fibers, magnesium, borium, folate and antioxidants. All these nutrients have an influence upon the cardiovascular diseases such as hypertension, diabetes mellitus, obesity and dyslipidemias. Studies have shown that total cholesterol plasmatic levels, low density lipoprotein (LDL), very low density lipoprotein (VLDL) and triglycerides in vegetarian individuals are lower when compared to omnivores individuals. Chylomicron metabolism $(\mathrm{Qm})$ and its lipoprotein lipase degradation products, the remnants, lipoproteins that transport dietary lipids in the blood has not yet been evaluated, although it is related to atherosclerosis. This study evaluated the plasmatic kinetics of artificial chylomicrons marked with triglycerides $\left({ }^{3} \mathrm{H}\right.$ TG) and cholesterol esters $\left({ }^{14} \mathrm{C}-\mathrm{CE}\right)$, as well as the qualitative aspects of $\mathrm{HDL}$ in 13 ovolacto-vegetarians (no ingestion of meat, chicken or fish), 10 vegan individuals (no ingestion of any food of animal origin) for more than 5 years and 14 omnivores individuals (ingestion of animal origin foods). All participants were normolipidemic, non diabetic and using no hypolipemiants medication. After an intravenous injection containing artificial Qms, blood samples were collected during 60 minutes at predetermined times. The radioactivity of each sample was measured and the fractional clearance rate (FCR) calculated for the radioactive lipids using compartmental analysis. Biochemical determinations were undertaken in order to calculate the post-heparin lipoprotein lipase activity in vitro. Also evaluated were the lipid transfer of the lipid nanoemulsion to the HDL and the diameter of the HDL particles. The plasma removal of the chylomicron remnants evaluated by the fractional clearance rate of the cholesteryl ester of the emulsion was greater in the vegan $(p<0,05)$ and ovolacto-vegetarian $(p<0,05)$ groups when compared to the omnivore group. The lipolysis of the chylomicron evaluated by the fractional clearance rate of the emulsion triglycerides and by the in vitro lipoprotein lipase activity assay was similar in 
the three studied groups. There were no differences in the plasma concentrations of HDL-C, VLDL-C and triglycerides between the three groups. The plasma concentrations of LDL-C and glucose of the vegan group were lower than omnivore group ( $p<0.05$ and $p<0.01$, respectively). In regards to total cholesterol, vegans present lower levels when compared to both ovolactovegetarians $(p<0.05)$ and omnivores $(p<0.01)$. No difference was found in the transfer of nanoemulsion lipids to HDL or in the size of the HDL of all three groups. These results suggest that the vegetarian diet can improve the metabolism of chylomicron remnants, atherogenic lipoproteins, which can be related to the beneficial effects of this diet upon the atherosclerosis process.

Descriptors: Lipids, lipoproteins, chylomicrons, chylomicron remnants, diet, vegetarian and atherosclerosis. 
INTRODUÇÃO 


\section{INTRODUÇÃO}

\subsection{Dieta vegetariana}

Indivíduos vegetarianos são aqueles que se abstêm do consumo de qualq5er tipo de carne animal, inclusive peixes e frutos-do-mar ou produtos que contenham esses alimentos. a dieta vegetariana é apropriada para todos os estágios do ciclo da vida, incluindo gravidez, lactação, infância e adolescência (MESSINA et al., 2001; HEBBELINCK et al., 2001; MANGELS, 2001). De acordo com a American Dietetlc Association (ADA) (CRAIG e MANGELS, 2009), as dietas vegetarianas, apropriadamente planejadas, são saudáveis e adequadas em termos nutricionais, trazendo benefícios para a prevenção e para o tratamento de determinadas doenças.

Existe uma grande heterogenicidade entre os indivíduos vegetarianos, no que diz respeito aos hábitos resultantes da mudança alimentar (MESSINA et al., 1996). As três principais dietas vegetarianas mais conhecidas e com maior número de adeptos são: a dieta ovolactovegetariana, baseada em grãos, vegetais, frutas, legumes, sementes, oleaginosas, laticínios e ovos. A dieta lacto-vegetariana exclui ovo bem como carne, peixe e frango. A dieta vegana ou vegetariana estrita é 
semelhante ao padrão da ovolacto-vegetariana, exceto pela exclusão adicional de ovos, laticínios e outros produtos de origem animal (CRAIG e MANGELS, 2009).

As razões para a adoção da dieta vegetariana incluem fatores racionais e emocionais. Entre elas, a principal razão é a saúde, pois existe um forte consenso que a dieta vegetariana é mais saudável do que as dietas que incluem alimentos de origem animal. Existem ainda outros motivos para adesão da dieta vegetariana como a ética e direitos dos animais, redução da destruição do meio ambiente, pois a criação industrial de animais traz profundos impactos ambientais e a fome, já que para cada quilograma de carne produzida são necessários cinco de grãos. A religião é uma outra razão, embora os motivos que levam uma instituição religiosa a recomendar esse regime alimentar baseiam-se em questões de saúde ou na crença de que matar é estritamente errado. A maioria das pessoas que adotam esse regime alimentar baseia sua escolha num estilo de vida mais saudável (MELINA et al., 1998; SABETÉ, 2003 ).

O interesse e a adesão ao vegetarianismo têm sido crescentes (JOHNSTON, 2003; CRAIG e MANGELS, 2009). De acordo com uma pesquisa nacional realizada nos Estados Unidos (EUA) em 2005, cerca de $3 \%$ de crianças e adolescentes com idade entre 8 e 18 anos são vegetarianos e 1\% são veganos (STAHLER, 2005). Outra pesquisa realizada em 2006 mostrou que aproximadamente 2,3\% da população adulta americana (4,9 milhões de pessoas) seguem uma dieta vegetariana e 1,4\% são veganos (STAHLER, 2006). 
Durante os últimos 20 anos, estudos epidemiológicos têm documentado importantes e significativos benefícios do vegetarianismo e outras dietas baseadas em alimentos vegetais, reduzindo o risco para muitas doenças crônicas não- transmissíveis (HU et al.,2000; STAMPFER et al., 2000; LIU et al., 2001; KEY et al., 2009), como também para o risco de mortalidade total (SABETÉ J, 2003).

Enquanto a ingestão de carne tem sido relacionada ao aumento do risco de uma gama de doenças crônicas não-transmissíveis como doença isquêmica do coração e alguns tipos de câncer, o abundante consumo de alimentos essenciais da dieta vegetariana, como frutas e hortaliças, leguminosas, alimentos não-refinados e nozes, tem sido consistentemente associado a um menor risco de contração dessas doenças e em alguns casos, a um aumento da expectativa de vida (KEY et al., 1999). Vários estudos têm demonstrado uma diminuição no risco de doenças cardiovasculares entre indivíduos vegetarianos (HU et al., 2003; BARNARD et al., 2006; TEIXEIRA et al., 2007; CHEN et al., 2008; CRAIG e MANGELS, 2009, FRASER, 2009). Além dos efeitos benéficos na incidência de doença arterial coronariana (DAC) e na progressão da aterosclerose coronária (ARNTZENIUS et al., 1985; KEY et al., 1999, DAVEY et al., 2003), dados da literatura mostram benefícios da dieta vegetariana na prevenção e tratamento de doenças digestivas (BURKITT et al., 1972; GEAR et al., 1977; BARKER et al., 1986), metabólicas (ELLIS et al., 1972; SNOWDON et al., 1985; TONSTAD et al., 2009), renais (ROBERTSON et al., 1979; 
BARSOTTI, 1991; MALHOTRA, 1993) e infecciosas (ACHA e SZYFRES, 1989; BERNSTEIN et al., 2007).

A dieta vegetariana difere da dieta onívora em aspectos que vão além da simples supressão de produtos cárneos. Os vegetarianos fazem um consumo elevado de vegetais, frutas, cereais, legumes e nozes, além de sua dieta conter menor conteúdo calórico, menor quantidade de gordura saturada e, relativamente, maior quantidade de gordura poliinsaturada, carboidratos, fibras, magnésio, boro, folato, e antioxidantes como vitamina $\mathrm{C}$ e E, carotenóides, flavonóides e outros fitoquímicos (JANELLE e BARR, 1995; JACOB e BURRI, 1996; MESSINA e MESSINA, 1996; KEY et al., 1999; CRAIG e MANGELS, 2009). Todos esses nutrientes influenciam e contribuem para uma diminuição dos fatores de risco de doenças cardiovasculares (DCV) em indivíduos vegetarianos, como hipertensão arterial (APPLEBY et al., 2002; ACOSTA et al., 1998; TEIXEIRA et al., 2007), resistência à insulina (BARNARD, 2005), diabete mellitus (SNOWDON et al., 1985; BARNARD et al., 2006; CRAIG e MANGELS, 2009; TONSTAD et al., 2009), obesidade (APPLEBY et al., 1999; BRAITHWAITE et al., 2003; VANG et al., 2008; CRAIG e MANGELS, 2009) e dislipidemia (DE BIASE et al., 2007; TEIXEIRA et al., 2007). Indivíduos que seguem uma dieta vegana, comparado com as outras dietas vegetarianas (ovolactovegetariana e lacto-vegetariana) tendem a consumir menos gordura saturada e colesterol e mais fibras (CRAIG, 2009). 


\subsection{Metabolismo de lípides e dieta vegetariana}

Dentre os fatores de risco de doenças cardiovasculares, o metabolismo de lípides plasmáticos apresenta um papel central. Vários estudos que avaliaram o perfil lipídico em inidvíduos vegetarianos têm demonstrado menores concentrações plásmaticas de colesterol total (KEY et al., 1999; RESNICOW et al., 1991; DE BIASE et al., 2007; TEIXEIRA et al., 2007). Em relação aos níveis plasmáticos de triglicérides (TG) alguns trabalhos mostram uma diminuição (FAMODU et al., 1998; LU et al., 2000, DE BIASE et al., 2007), e outros não encontraram diferenças significativas (LIN et al., 2001; CHELCHOWSKA et al., 2003).

Em relação às lipoproteínas plasmáticas, indivíduos vegetarianos possuem níveis plasmáticos menores de colesterol de lipoproteína de baixa densidade (LDL-C) (SACKS et al., 1975; MELBY et al., 1994; LI et al., 1999; CHELCHOWSKA et al., 2003; RICHTER et al., 2004; WALDMMAN et al., 2005; CHEN et al., 2008). Em relação ao colesterol de lipoproteína de alta densidade (HDL-C), os resultados dos estudos são controversos, sendo que alguns estudos mostram uma diminuição (SACKS et al., 1975; MESSINA e MESSINA, 1996; RICHTER et al., 2004) e outros não encontraram alterações em seus níveis (KORPELA et al., 1999; LU et al., 2000; CHELCHOWSKA et al., 2003; CHEN et al., 2008). Além disso, estudos de intervenção dietética mostraram que indivíduos onívoros, submetidos à dieta 
vegetariana apresentaram alterações benéficas no perfil lipídico (COOPER et al., 1982; LITHELL, 1985; KNUTSEN e HOGGANVIK, 1988; LING, 1992, MAHON AK, et al., 2007).

Em diversos estudos que avaliam a influência de patologias, intervenção medicamentosa, dietética, etc, no metabolismo lipídico, as avaliações lipídicas são realizadas no jejum, através da simples determinação da concentração dos lípides plasmáticos. Desta maneira, a avaliação do metabolismo dos quilomícrons (Qm), lipoproteínas que transportam os lípides da dieta na circulação sanguínea, tem sido negligenciada e não existem dados na literatura mostrando essa avaliação em indivíduos vegetarianos. Entretanto, vários trabalhos têm demonstrado o papel aterogênico dos quilomícrons, lipoproteínas responsáveis pelo transporte, na circulação sanguínea, dos lípides provenientes da dieta (MARANHÃO et al., 1996, MEYER et al., 1996, WEINTRAUB et al., 1996).

\subsection{Metabolismo da Lipoproteína de Alta Densidade (HDL)}

A HDL também é uma lipoproteína que desempenha importante papel no transporte endógeno de lípides, no plasma. É constituída por 45 a 55\% de proteínas, 26 a 32\% de fosfolípides, 15 a 20\% de colesterol esterificado, 
3 a 5\% de colesterol livre e 2 a 7\% de triglicérides (GOTTO et al., 1983) . Corresponde a um grupo heterogêneo de partículas e apresenta uma meiavida de 5 a 6 dias, a mais longa de todas as lipoproteínas (BACHORIK, et al., 1999; KWITEROVICH et al., 2000). A HDL é sintetizada principalmente no fígado, inicialmente em forma discóide, com alto conteúdo de colesterol livre e também composta de fosfolípides e apos, principalmente apo A-I e apo E. Dependendo do seu conteúdo lipídico, da quantidade de proteínas e, consequentemente, do seu tamanho, a HDL pode ser dividida em quatro subclasses: $\mathrm{HDL}_{1}$. $\mathrm{HDL}_{2}, \mathrm{HDL}_{3} \mathrm{HDL}_{4}$. Sendo que as populações de $\mathrm{HDL}_{2} \mathrm{e}$ $\mathrm{HDL}_{3}$ estão presentes em maior concentração no plasma (EISENBERG, 1984). Outras espécies de apoliproteínas são encontradas nessa partícula incluindo, apoAII, apo AIV, apo Cl e apo CIII (DUCHATEAU et al., 1997). As diferenças no tamanho da partícula de HDL são atribuídas principalmente ao número de apoproteínas encontradas na sua superfície e a quantidade de éster de colesterol presente no seu interior (BARTER, 2004).

As partículas de HDLs captam o excesso de colesterol livre das células dos tecidos periféricos e da superfície das lipoproteínas ricas em triglicérides, sendo convertidas a partículas menores, as $\mathrm{HDL}_{3}$. A apo A-I presente na lipoproteína é um cofator de ativação da Lecitina Colesterol Acil Transferase (LCAT), uma enzima sintetizada e secretada principalmente no fígado, presente na circulação e que se liga a superfície das lipoproteínas, inclusive da HDL, a qual esterifica o colesterol livre da $\mathrm{HDL}_{3}$ em uma partícula maior, a HDL 2.(ECKADSTEIN et al., 2001). A $\mathrm{HDL}_{2}$ realiza trocas de ésteres de colesterol e triglicerídeos, com as demais lipoproteínas, os 
quilomícrons, a lipoproteína de muito baixa densidade (VLDL), a lipoproteína de densidade intermediária (IDL) e a LDL, em um processo mediado pela proteína de transferência de éster de colesterol (CETP), uma glicoproteína hidrofóbica, produzida pelo fígado e que está presente no plasma em associação com as lipoproteínas (LEWIS et al., 2006). O colesterol esterificado é transferido, por meio da CETP, da $\mathrm{HDL}_{2}$, para as demais lipoproteínas ricas em triglicerídeos. A extensão da transferência depende da concentração de cada componente lipídico na lipoproteína doadora (GLOMSET et al., 1970; MARCEL et al., 1980; EISEMBERG, 1984). A interação da $\mathrm{HDL}_{3}$ com as células da parede arterial nesse processo de retirada do colesterol livre é mediada por um receptor específico, de superfície celular, com especificidade para a apo A-I. A HDL rica em colesterol esterificado é captada pelo fígado através de receptores celulares específicos que reconhecem a apo $E$ (receptores $B / E)$.

O efeito anti-aterogênico da HDL se dá, sobretudo devido a sua propriedade de transportar lipídeos, principalmente ésteres de colesterol, dos tecidos periféricos para o fígado e para os tecidos que produzem hormônios esteróides, onde o colesterol é utilizado para a síntese de lipoproteínas, sais biliares, vitamina D e hormônios, efeito conhecido como transporte reverso do colesterol (TRC) (ECKARDSTEIN et al., 2001). O transporte de colesterol dos tecidos periféricos pra o fígado é uma das mais importantes funções HDL. Nesse transporte reverso é envolvida uma variedade de tecidos e moléculas que impedem que o colesterol se acumule nas células. Sendo bastante complexo, esse transporte envolve, a nível 
celular, enzimas que hidrolizam a ligação éster do colesterol e o sistema "ATP-binding cassete transporter A1" (ABCA1), que possibilitam a captação do colesterol livre, pela HDL (YANCEY et al., 2003). No compartimento plasmático, há o envolvimento das proteínas de transferência, da LCAT, e finalmente, dos receptores celulares de lipoproteínas no fígado.

A HDL também desempenha a importante função de doar apolipoproteínas para as lipoproteínas ricas em triglicérides, necessárias ao metabolismo das mesmas. Além da importante função no transporte reverso do colesterol, a HDL também está envolvida com proteção da função endotelial e mecanismos de proteção contra processos oxidativos de lipoproteínas.

\subsection{Metabolismo de Quilomícrons}

Após a absorção das gorduras no intestino, os quilomícrons são secretados na linfa mesentérica, com diâmetro variando de 75 a 1200 nm. O número, tamanho e composição dos quilomícrons dependem do aporte e da natureza dos lípides absorvidos, sendo que geralmente durante o pico de absorção de lípides, ocorre a formação de partículas de maior tamanho. Os quilomícrons são constituídos por 80 a 95\% de triglicérides, 2 a 4\% de 
colesterol esterificado (CE), 3 a 6\% de fosfolípides (FL), 1 a 3\% de colesterol livre (CL) e 1 a $2 \%$ de proteínas (REDGRAVE, 1983).

Após a secreção nos capilares linfáticos intestinais, os quilomícrons interagem com outras lipoproteínas presentes na linfa, principalmente a HDL, de quem recebe apolipoproteínas (apos) C e E e doa apo A-I e apo AIV, além de perder fosfolípides. Os quilomícrons possuem predominantemente as apos A-I, C-I, C-II e C-III e quantidades menores de apos E, A-IV e B-48.

Através do ducto torácico, os quilomícrons atingem a circulação sistêmica, onde passam por um processo de intensa catabolização. Continuam ocorrendo colisões entre os quilomícrons e outras lipoproteínas, principalmente a lipoproteína de alta densidade (HDL), com consequentes trocas de elementos de superfície (PATSCH, 1998).

O processo de catabolismo dos quilomícrons se inicia com uma enzima sintetizada nas células endoteliais, a lipase lipoprotéica (LLP). Os quilomícrons possuem em sua superfície uma apolipoproteína, a apo Cll que é um cofator de ativação da LLP. Uma vez ativada, essa enzima inicia o processo de hidrólise dos triglicérides dos quilomícrons (BLANCHETTEMACKIE, 1973; HUSSAIN et al., 2005). As partículas resultantes do processo de lipólise apresentam um diâmetro menor (40 a 60 nm) e são denominadas remanescentes de quilomícrons (Qm-r) (WINDLER et al., 1988).

Durante o catabolismo dos quilomícrons, ocorrem trocas de componentes lipídicos com outras lipoproteínas, principalmente triglicérides 
dos quilomícrons para as HDLs e de colesterol esterificado das HDLs para os quilomícrons, através da proteína de transferência de ésteres de colesterol (CETP). O colesterol esterificado pode ser transferido, através da CETP, das $\mathrm{HDL}_{2}$ para as lipoproteínas ricas em triglicérides e para as LDL (GLOMSET, 1970).

Os remanescentes de quilomícrons, formados a partir do catabolismo dos quilomícrons pela ação da LLP, apresentam um conteúdo menor de triglicérides em cerca de $85 \%$. Os remanescentes transportam para o fígado o colesterol plasmático de origem da dieta, que pode ser utilizado na síntese de membranas celulares, na síntese de outras lipoproteínas de origem hepática ou ainda ser excretado na bile, na forma de ácidos biliares (BROWN et al., 1981).

Após a captação do remanescente pelas células hepáticas através da apo E, o colesterol derivado do catabolismo dessas partículas pode suprimir a expressão de receptores de LDL e desta maneira, influenciar nas concentrações plasmáticas de LDL-C (BROWN et al., 1986). O remanescente é capaz de inibir a síntese hepática de colesterol, reduzindo, desta maneira os níveis de colesterol endógeno secretado no plasma (NERVI et al., 1975). 


\subsection{Lipase Lipoprotéica}

A LLP apresenta um papel muito importante no metabolismo de lipoproteínas ricas em triglicérides, sendo a principal enzima responsável pela hidrólise de moléculas de triglicérides presentes nessas lipoproteínas. Alguns autores têm sugerido que a captação hepática de lipoproteínas pode ser mediada pela LLP; portanto essa enzima pode ter um importante papel no metabolismo dos quilomícrons, não somente pela sua atividade lipolítica, mas também pelas propriedades estruturais (BEISEGIEL et al., 1991, OTAROD et al., 2004; BISHOP JR et al., 2008).

A LLP é uma glicoproteína sintetizada e secretada por células parenquimatosas de vários tecidos extra-hepáticos, principalmente músculo e tecido adiposo (QUINN et al., 1982) e transportada para as células endoteliais na superfície dos vasos (WANG \& ECKEL, 2009).

O receptor de LLP é uma substância "heparin like" (QUINN et al., 1982). Existe uma grande afinidade de ligação da heparina às lipases e por esse motivo as enzimas aderidas à superfície endotelial são rapidamente liberadas na circulação sanguínea pela heparina. A heparina causa a liberação da LLP na circulação sanguínea, através de alterações na ligação eletrostática entre a enzima e seu receptor. A injeção de heparina no homem pode aumentar a atividade da LLP cerca de 1.000 vezes, com um aumento de 10 vezes na massa da enzima, na circulação sanguínea. A atividade da 
LLP pré-heparina é 0,3 - 1 miliunidades/ml. Após uma refeição rica em gordura, a atividade aumenta para 2 - 3 miliunidades $/ \mathrm{ml}$ e após a injeção de heparina, para 150 - 300 miliunidades $/ \mathrm{ml}$. A massa de LLP circulante varia de 8 a $25 \mathrm{ng} / \mathrm{ml}$, aumentando para $0,1-2,0 \mathrm{mg} / \mathrm{ml}$ no plasma pós-heparina (BEISEGIEL et al., 1991).

A atividade da LLP pode também regular os níveis plasmáticos do HDL-C. Além de sua ação enzimática, a LLP pode facilitar a remoção plasmática dos remanescentes de quilomícrons, aumentando a ligação dessas lipoproteínas com a proteína relacionada ao receptor de LDL (LRP), receptores envolvidos na captação das mesmas, sendo que a ligação pode estar reduzida em células com deficiência de sulfato de heparana (SH) (BEISEGIEL et al., 1991; BISHOP et al., 2008).

\subsection{Metabolismo de Quilomícrons e Aterosclerose}

No início da década de 70 , estudos já demonstravam que o colesterol e a gordura provenientes da dieta, principalmente a gordura saturada, eram fatores aterogênicos. Entretanto, atribuia-se o seu papel no processo aterosclerótico a alterações nas concentrações plasmáticas de colesterol.

O fato dos quilomícrons serem as lipoproteínas responsáveis pelo transporte do colesterol da dieta na circulação sanguínea e da primeira 
etapa de sua degradação ocorrer em contato com o endotélio vascular, levou Zilversmith a avaliar a possibilidade dos quilomícrons serem por si próprios, aterogênicos (ZILVERSMITH et al., 1979).

Tem sido demonstrado o papel aterogênico dos quilomícrons e seus remanescentes (MARANHÃO et al., 1996; MEYER et al., 1996; WEINTRAUB et al., 1996; SPÓSITO et al., 2004, LEKHAL et al., 2008) e sua relação com o desenvolvimento (PATSCH et al., 1992; KOLOVOU et al., 2005) e com a progressão de doença arterial coronariana (KARPE et al., 1994). A duração e a magnitude da lipemia pós-prandial em pacientes hipertrigliceridêmicos é muito maior que em indivíduos normolipidêmicos, sugerindo que a exposição prolongada do endotélio vascular aos quilomícrons e seus remanescentes pode ter um papel importante na incidência aumentada de doença arterial coronariana nesses pacientes (RASSIN et al., 1992). Tanto o processo de lipólise de quilomícrons, como a captação hepática dos remanescentes podem estar envolvidos com a aterogênese.

O acúmulo de remanescentes de quilomícrons na circulação sistêmica pode ser causado principalmente por deficiência de receptores específicos na superfície das células hepáticas ou por deficiência funcional da apo $E$, presente na superfície dessas lipoproteínas. O maior tempo de permanência dos remanescentes na circulação sanguínea pode levar à deposição de colesterol na parede arterial, o que pode colaborar com o processo aterogênico (MAMO e WHEELER, 1994; PROCTOR e MAMO, 1996). 
Tanto os quilomícrons e seus remanescentes por si próprios como também os processos metabólicos envolvidos no metabolismo dos remanescentes podem estar relacionados com a aterogênese.

Nesse sentido, os remanescentes são captados por macrófagos e induzem acúmulo de colesterol nessas células o que leva à formação de células espumosas a um grau comparável ao da LDL oxidada (FLOREN e CHAIT, 1981; VAN LENTEN et al., 1985; ELLSWORTH et al., 1987; KOO et al. 1988; ELLSWORTH et al., 1990; FUJIOCA et al., 1998; YU e MAMO, 2000; ELSEGOOD et al., 2001; NAPOLITANO et al., 2001; YU e COOPER, 2001; BATT et al., 2004; BOTHAM et al., 2005). Os remanescentes também podem causar injúria endotelial por indução de apoptose (KUGIYAMA et al., 1998; KAWASAKI et al., 2000), prejudicar a vasodilatação endotélio dependente e inibir a atividade da óxido nítrico sintase (eNOS) e a produção de óxido nítrico. Além disso, os remanescentes também podem aumentar a expressão de moléculas de adesão e provavelmente estão envolvidos com a inibição da atividade da telomerase, com a senescência de células progenitoras endoteliais (DOI et al., 2000), com estímulo da proliferação de células musculares lisas (KAWAKAMI et al., 2001) e com o aumento da agregação plaquetária (SANIABADI et al.,1997). 


\subsection{Metodologias para Avaliação do Metabolismo de Quilomícrons}

A avaliação do metabolismo de lipoproteínas normalmente é realizada através da determinação de seu conteúdo lipídico e/ou protéico. Entretanto, diversos fatores têm dificultado o estudo do metabolismo de quilomícrons e seus remanescentes no homem. A remoção plasmática de quilomícrons é um processo complexo, afetado por vários fatores, que ocorre em um espaço de tempo muito pequeno. Esse fato torna difícil o estudo desse circuito metabólico.

Outro fator que dificulta a avaliação da cinética de quilomícrons é a natureza da partícula produzida, cujo tamanho e composição variam de acordo com a quantidade de material inicial, com a presença de albumina e com a disponibilidade de outras lipoproteínas para troca de componentes (HUSSAIN et al., 1996).

Os estudos de remoção dos quilomícrons da circulação sanguínea têm sido realizados através de vários métodos:

1- Avaliação da cinética plasmática de triglicérides após a ingestão de gordura (SCHNEEMAN et al., 1993), o teste de tolerância. O teste consiste na ingestão de uma dieta rica em gordura, seguida de coletas de amostras de sangue em tempos pré-determinados, para determinação das concentrações plasmáticas de triglicérides. 
2- Avaliação da cinética plasmática do retinil palmitato após a ingestão de gordura suplementada com vitamina A (COHN et al., 1993).

3- Avaliação da cinética plasmática de lípides marcados com radioisótopos ingeridos com a gordura (DUBOIS et al., 1996). Permite a diferenciação entre quilomícrons e seus remanescentes, porém, apresenta a variável do período gasto para a absorção da gordura ingerida.

4- Avaliação da cinética plasmática de quilomícrons autólogos colhidos após a ingestão de gordura enriquecida com retinil palmitato e injetados endovenosamente (BERR, KERN, 1984).

Na década de 80, foram descritas emulsões lipídicas artificiais com composição lipídica e densidade semelhantes ao quilomícron natural. Essas emulsões são destituídas de proteínas, porém quando injetadas na circulação sanguínea, adquirem as diversas apos, através de colisões com outras lipoproteínas, com consequentes trocas de componentes de superfície (MARANHÃO et al., 1984). Estudos realizados em ratos mostraram que quando injetada endovenosamente, as emulsões apresentam comportamento metabólico similar ao quilomícron natural (HIRATA et al., 1987). Outra demonstração da similaridade do metabolismo das emulsões artificiais e dos quilomícrons naturais foi mostrada em humanos, através da observação da cinética plasmática mais lenta das emulsões artificiais após uma refeição rica em gordura, o que sugere que ocorra uma competição das emulsões com os quilomícrons naturais (MARANHÃO et al., 1996). Essa metodologia apresenta a vantagem de ultrapassar as etapas de absorção e formação de quilomícrons no intestino. 
Além disso, o teste é de fácil aplicação e possibilita acompanhar o metabolismo de quilomícrons, através da utilização de isótopos radioativos.

Através da avaliação da remoção plasmática das emulsões artificiais, podem ser avaliados os efeitos de regimes dietéticos e diversas drogas em diversos aspectos dinâmicos no circuito metabólico dos quilomícrons. O modelo de emulsões artificiais, como estratégia para avaliação do metabolismo das lipoproteínas pós-prandiais, tem sido utilizado em diversas condições patológicas como doença arterial coronariana (MARANHÃO et al., 1996; SPÓSITO et al., 2002; CHACRA et al., 2004), lúpus eritematoso sistêmico (BORBA et al., 2000), hipertensão arterial maligna (BERNARDESSILVA et al., 1995), transplante cardíaco (VINAGRE et al., 2000), entre outros.

Já se encontra estabelecido que a dieta vegetariana exerce efeitos benéficos nas concentrações de lípides plasmáticos. Entretanto, as determinações de lípides plasmáticos realizados até o momento em indivíduos vegetarianos foram efetuadas em jejum, ficando negligenciada a avaliação do metabolismo das lipoproteínas pós-prandiais, os quilomícrons e seus remanescentes. Visto serem os quilomícrons, lipoproteínas aterogênicas e estarem presentes na circulação grande parte do dia, é de grande interesse o conhecimento da influência de dietas no metabolismo dessas lipoproteínas, como os efeitos da dieta vegetariana. O tipo e a quantidade de gordura na dieta, assim como o metabolismo das lipoproteínas ricas em triglicérides (quilomícrons e VLDL), podem influenciar 
os níveis plasmáticos de HDL-C. Neste sentido, os resultados da literatura são controversos, mostrando diminuição ou nenhuma alteração nas concentrações dessa lipoproteína. Os efeitos da dieta vegetariana em aspectos qualitativos da HDL não foram investigados e podem ser de grande importância em sua função anti-aterogênica.

Neste trabalho, foram estudados os efeitos da dieta vegetariana no metabolismo intravascular dos quilomícrons, através da utilização de emulsões lipídicas artificiais com conteúdo lipídico e comportamento metabólico similares aos das lipoproteínas naturais as quais permitem um maior conhecimento de aspectos metabólicos dos quilomícrons. Além disso, foi calculado o diâmetro da HDL e através de nanoemulsões artificiais ricas em colesterol (LDE), foi realizado estudo de transferência de lípides para a HDL. 


\section{OBJETIVOS}

\subsection{Objetivos Gerais}

O presente estudo teve como objetivo, avaliar o metabolismo de quilomícrons em indivíduos adeptos à dieta vegetariana e aspectos qualitativos da HDL.

\subsection{Objetivos Específicos}

Avaliar os efeitos da dieta vegetariana:

- Na cinética plasmática de quilomícrons: processo lipolítico dos quilomícrons e remoção plasmática dos remanescentes de quilomícrons

- Na atividade da lipase lipoprotéica 
- Nas concentrações dos lípides e lipoproteínas plasmáticas

- Na transferência de lípides da nanoemulsão da LDE para a HDL

- No diâmetro da HDL 
CASUÍSTICA, MATERIAL E MÉTODOS 


\section{CASUÍSTICA, MATERIAL E MÉTODOS}

\subsection{Casuística}

Foram avaliados 68 indivíduos:

1. 18 ovolacto-vegetarianos (OLV) - aqueles que tem uma alimentação baseada em grãos, vegetais, frutas, legumes, sementes, oleaginosas, leite, ovos e derivados, mas com restrição do consumo de qualquer tipo de carne e produtos derivados.

2. 21 veganos $(\mathrm{V})$ - aqueles que não consomem nenhum tipo de alimento de origem animal, excluindo, dessa maneira, carne e também o leite, ovos e derivados.

3. 29 onívoros $(\mathrm{ON})$ - aqueles que consomem qualquer alimento de origem vegetal e animal.

O número de participantes do estudo foi baseado em trabalhos anteriores, que utilizaram a mesma metodologia para avaliação do metabolismo de quilomícrons (HOSNI et al., 2007; CÉSAR et al., 2006; DE MARCHI et al., 2006). Todos os participantes eram voluntários saudáveis e estavam praticando a dieta (ovolacto- vegetariana, vegana ou onívora), por pelo menos 5 anos prévios ao início do estudo. Os indivíduos vegetarianos foram recrutados através da divulgação do estudo, no site 
www.alimentacaosemcarne.com.br. Os interessados em participar entravam em contato para marcar uma primeira visita. Nesse primeiro dia, os indivíduos respondiam a um questionário sobre hábitos de vida, alimentação, e atividade física (Anexo 1). Através desse questionário, os participantes foram selecionados e subdivididos nos grupos para participarem da pesquisa. No dia da realização dos testes, os indivíduos respondiam a uma recordatório alimentar, incluindo dois dias da semana e um dia do final de semana. Através deste recordatório foi calculada, pelo software profissional Diet Win Análise Nutricional, a ingestão de energia e macronutrientes de todos os participantes.

Os participantes foram pareados por sexo, idade e índice de massa corpórea (IMC).

Critérios de inclusão:

- Ser adepto à dieta vegetariana, vegana ou ovolactovegetariana

- Idade entre 20 de acordo com a recomendação do ATP III e 55 anos

- Índice de Massa Corpórea (IMC) entre $18,4 \mathrm{Kg} / \mathrm{cm}^{2}$ e $24,9 \mathrm{Kg} / \mathrm{cm}^{2}$

Critérios de exclusão - presença de:

- Dislipidemias - Critérios do National Cholesterol Education Program Adult Treatment Panel (NCEP-ATP-III):

1. Hipercolesterolemia: $\geq 200 \mathrm{mg} / \mathrm{dL}$ 
2. Hipertrigliceridemia: $\geq 150 \mathrm{md} / \mathrm{dL}$

3. HDL-C baixo: $<40 \mathrm{mg} / \mathrm{dL}$ para homens

$<50 \mathrm{mg} / \mathrm{dL}$ para mulheres

- Diabetes Mellitus - Critério do Expert Committe on Diagnosis of Diabetes Mellitus: glicemia em jejum > $126 \mathrm{mg} / \mathrm{dL}$

- Doença aterosclerótica

- Fumantes

- Obesidade, em função do IMC: Critério recomendado pelo NCEPATP-III: IMC $>30 \mathrm{~kg} / \mathrm{cm}^{2}$

- Insuficiência renal

- Insuficiência hepática

- Hipertensão arterial

- Hipotireodismo

- Uso de medicamentos como corticóides, diuréticos, betabloqueadores, progestágenos, anabólicos esteróides, imunossupressores e hipolipemiantes.

- Idade inferior a 20 anos e superior a 55 anos.

- Gestação, confirmada por teste de gravidez, no dia dos estudos cinéticos.

- Praticante de atividade física intensa (mais que 4 vezes por semana)

Os participantes foram orientados detalhadamente sobre os objetivos do estudo, assim como todos os procedimentos envolvidos no protocolo de pesquisa. Após todos os esclarecimentos, assinaram um termo de 
consentimento prévio (Anexo 2), antes do questionário alimentar e da realização dos testes no laboratório.

\subsection{Material}

Os lípides, colesterol, oleato de colesterol, trioleína e fosfolípides foram obtidos da Sigma Chemical Co (St. Louis, USA). Os lípides marcados radioisotopicamente, glycerol tri[9,10(n) $\left.{ }^{3} \mathrm{H}\right]$ oleate e cholesteryl $\left[1-{ }^{14} \mathrm{C}\right]$ oleate foram obtidos da Amersham International (UK). A sílica gel $60 \mathrm{H}$ e sistema solvente constituído de hexano: éter etílico: ácido acético (70: 30: 1, v/v) (Merck S.A Indústrias Químicas, Rio de Janeiro, Brasil) foi utilizada para verificar a pureza dos lípides, através de cromatografia em camada delgada (0,05 $\mathrm{mm}$ de espessura).

O tolueno, triton-X, POPOP e PPO, utilizados no preparo da solução cintiladora, o clorofórmio e o metanol utilizados no método de extração de lípides foram obtidos da Merck S.A Indústrias Químicas (Rio de Janeiro, Brasil).

A heparina sódica (Liquemine,) utilizada como anticoagulante nas amostras de sangue colhidas dos participantes do estudo e nos ensaios de medida de atividade lipolítica, será obtida da Roche (Brasil). 


\subsection{Métodos}

\subsubsection{Preparo da Emulsão de Quilomícrons Artificiais}

As emulsões de quilomícrons artificiais foram preparadas conforme descrito anteriormente (MARANHÃO et al., 1984). Os lípides frios foram dissolvidos em clorofórmio: metanol, 2:1 e pipetados em frascos de cintilação (2\% colesterol, $6 \%$ oleato de colesterol, $23 \%$ lecitina e $69 \%$ trioleína), juntamente com os lípides radioativos oleato de colesterol- $-{ }^{14} \mathrm{C}$ e trioleina $-{ }^{3} \mathrm{H}$. As misturas passaram por um processo de secagem sob fluxo de nitrogênio e foram mantidas durante 12 horas em dessecador à vácuo para completa evaporação dos solventes orgânicos residuais. Foram acrescentadas às misturas secas, $6,0 \mathrm{ml}$ de solução de $\mathrm{NaCl}$, densidade $1,101 \mathrm{~g} / \mathrm{mL}, \mathrm{pH} 7,0$.

As emulsões foram preparadas através de irradiação ultrassônica das misturas lipídicas em meio aquoso salino, utilizando-se um disrruptor de células, Branson Cell Disruptor (Branson Ultrasonics Corp, mod B 450), equipado com ponta de titâneo com $1 \mathrm{~cm}$ de diâmetro, com uma potência de 70-80 watts, durante 30 minutos, sob fluxo de nitrogênio em uma temperatura de 50 a $55^{\circ} \mathrm{C}$. As emulsões obtidas foram submetidas a duas 
etapas de ultracentrifugação em gradiente descontínuo de densidade, utilizando-se rotor TH 641e ultracentrífuga Sorvall (modelo OTD Comb, Wilmington, EUA), para purificação, ou seja, obtenção de partículas homogêneas, com a densidade e o tamanho desejados. Na primeira etapa, foram acrescentadas ao volume das emulsões obtidas por irradiação ultrassônica, soluções salinas com densidades $1,065 \mathrm{~g} / \mathrm{mL}, 1,020 \mathrm{~g} / \mathrm{mL}$ e $1,006 \mathrm{~g} / \mathrm{mL}$, nesta ordem. As emulsões foram ultracentrifugadas a 12.000 rotações por minuto, a $22{ }^{\circ} \mathrm{C}$ durante 15 minutos. Ao término da ultracentrifugação, foram desprezados $0,5 \mathrm{~mL}$ do sobrenadante e o restante do volume foi submetido à segunda etapa de purificação, através de ultracentrifugação a 36.000 rotações por minuto, a $22 \stackrel{\circ}{\circ}$, durante 25 minutos. As emulsões utilizadas no presente estudo foram então obtidas através da aspiração de $3,0 \mathrm{~mL}$ do sobrenadante e imediatamente esterilizadas através de passagem em filtros com porosidade de 0,22 $\mu \mathrm{m}$ de diâmetro (Millipore, São Paulo) e armazenadas em frascos estéreis.

Toda a vidraria utilizada no preparo das emulsões foi submetida a um processo de despirogenização através de vapor seco, $180{ }^{\circ} \mathrm{C}$, durante 2 horas e esterilização em vapor úmido, $120{ }^{\circ} \mathrm{C}$, durante 30 minutos. Os materiais plásticos foram esterilizados através de exposição à luz ultravioleta de onda curta, as quais possuem um componente com comprimento de onda de 253,7 nanômetros, durante 12 horas. Todo o procedimento de preparo das emulsões foi realizado em sala isolada, em capela de fluxo laminar vertical. Alíquotas das emulsões artificiais foram submetidas a teste de esterilidade e pirogenicidade. 


\subsubsection{Preparo da Nanoemulsão Artificial Semelhante à LDL (LDE)}

A nanoemulsão LDE foi marcada com oleato de colesterol- ${ }^{14} \mathrm{C}$, trioleína $-{ }^{3} \mathrm{H}$, colesterol- ${ }^{3} \mathrm{H}$ e fosfolípides $-{ }^{14} \mathrm{C}$, para o estudo de transferência de lípides para a HDL. Segundo a técnica descrita por Ginsburg et al. (1982) e modificada por Maranhão et al. (1993), utilizamos o seguinte procedimento: em um frasco, foram pipetados $40 \mathrm{mg}$ de fosfatidilcolina, 20 de oleato de colesterol e $1 \mathrm{mg}$ de trioleína e 0,5 mg de colesterol (SigmaChemical Co - St Louis, EUA), a partir de estoques preparados em clorofórmio/metanol (2:1) (Merck-Darmstadt, Alemanha). Foram adicionados oleato de colesterol- ${ }^{14} \mathrm{C}$, trioleína, fosfolípides $-{ }^{14} \mathrm{C}$ e ${ }^{3} \mathrm{H}$-colesterol (Amersham Internacional - Reino Unido). Depois disso, a mistura foi submetida a um processo de secagem sob fluxo de nitrogênio, em banhomaria $37^{\circ} \mathrm{C}$ e mantida em dessecador a vácuo, por 16 horas, $4^{\circ} \mathrm{C}$, para remoção dos solventes residuais. A mistura de lípides ressuspendida em tampão tris- $\mathrm{HCl}$ foi emulsificada por irradiação ultrassônica de $125 \mathrm{~W}$ de potência, durante 3 horas, sob uma atmosfera de nitrogênio, com uma variação da temperatura de 51 a $55 \stackrel{\circ}{\circ}$. Em seguida, a nanoemulsão foi purificada através de duas etapas de ultracentrifugação e esterilizada através de passagem em filtro Millipore, 0,22 $\mu \mathrm{m}$ de diâmetro. 


\subsubsection{Estudos Cinéticos com a Emulsão de Quilomícrons Artificiais}

Os participantes chegavam ao laboratório após as 8 horas, em jejum de 12 horas. Após a coleta das amostras de sangue para as determinações bioquímicas (concentrações plasmáticas de colesterol total, LDL-C, HDL-C, VLDL-C e triglicérides), avaliação da transferência de lípides da nanoemulsão LDE para a HDL e medida do diâmetro da HDL, dava-se início aos estudos cinéticos da emulsão de quilomícrons artificiais. Utilizando-se a mesma veia, foi injetado cerca de $100 \mathrm{uL}$ de emulsão, contendo $148 \mathrm{kBq}$ (4uci) de ${ }^{3} \mathrm{H}$-trioleína e $74 \mathrm{kBq}(2 \mathrm{uCi})$ de ${ }^{14} \mathrm{C}$-oleato de colesterol. Após a injeção, através de outra punção venosa, foram colhidas amostras de sangue $(6,0 \mathrm{~mL})$ em tubos de ensaio contendo $50 \mathrm{uL}$ de heparina sódica, em intervalos de tempo pré-estabelecidos $(2,4,6,10,15,20,30,45$ e 60 minutos), mantendo-se a cateterização venosa com soro fisiológico 0,9\%. As amostras de sangue foram centrifugadas a $2.700 \mathrm{rpm}$, durante 10 minutos, em centrífuga Sorvall (modelo RT7, Wilmington, EUA), para obtenção de plasma. Alíquotas de $1,0 \mathrm{~mL}$ de plasma foram pipetadas em frascos de cintilação. Foram acrescentados a esses frascos, $7,0 \mathrm{~mL}$ de solução cintiladora PPO/POPOP/tritonX-100/tolueno (5g: 0,5g: $333 \mathrm{~mL}: / 667 \mathrm{~mL}$ ) para a determinação da radioatividade presente nas amostras, utilizando-se um contador Beta (Packard, modelo 1660 TR, EUA). As contagens obtidas 
foram utilizadas para o cálculo das curvas de decaimento plasmático e dos parâmetros cinéticos dos componentes lipídicos radioativos da emulsão.

\subsubsection{Ausência de Risco Relacionada aos Estudos Cinéticos}

A dose radiológica injetada foi avaliada de acordo com as normas da "International Commission on Radiological Protection" (ICRP) (SOWBY, 1984). O parâmetro "Annual Limit for Intake" (ALI) de radionuclídeo é definido como a quantidade de radioisótopo que induz a uma dose equivalente de $50 \mathrm{mSv}$. Para componentes orgânicos marcados com ${ }^{14} \mathrm{C}$ ou ${ }^{3} \mathrm{H}$, os valores de ALI são $9 \times 10^{7}$ e $3 \times 10^{9} \mathrm{~Bq}$, respectivamente. No presente estudo, a dose injetada de ${ }^{14} \mathrm{C}$ será de $22,2 \times 10^{4} \mathrm{~Bq}$, o que equivale a: $(22,2$ $\left.\times 10^{4} \mathrm{~Bq} / 9 \times 10^{7} \mathrm{~Bq}\right) \times 50 \mathrm{mSv}=0,1233 \mathrm{msV}$. Para $\circ{ }^{3} \mathrm{H}$, a dose injetada será de $44,4 \times 10^{4} \mathrm{~Bq}$, portanto a dose equivalente: $\left(44,4 \times 10^{4} \mathrm{~Bq} / 3 \times 10^{9}\right.$ $\mathrm{Bq}) \times 50 \mathrm{mSv}=0,0075 \mathrm{mSv}$.

A dose equivalente incorporada no corpo inteiro em consequência da exposição aos lípides radioativos foi estimada em 0,04 mSv, conforme avaliado pelo método MIRD - Medical Internal Radiological Dosimetry (SMITH, 1977). Em conformidade com as normas de proteção radiológica 
(Comissão Nacional de Energia Nuclear, 1988), este valor é muito inferior ao máximo permitido, $50 \mathrm{mSv}$.

Os dados descritos para ratos pesando $0,4 \mathrm{~kg}$ foram ajustados para seres humanos, estimando-se um peso médio de $70 \mathrm{~kg}$, utilizando-se um fator de correção com a equação seguinte:

KHomen $=$ kRato $\times(70 \mathrm{~kg} / 0,4 \mathrm{~kg})^{1-x}$.

O valor exponencial $X$ representa uma escala de variações interespécies da farmacocinética, levando em consideração o tempo biológico de cada espécie, que varia de 0,65 a 0,95. Considerando o valor de $X=0,86$, estima para os seres humanos um nível plasmático total de 204 mg/dL e uma excreção diária de colesterol de 1250 mg/dia (BOXENBAUM, RONFELD,1983).

Esse valor está dentro da média descrita em avaliações laboratoriais desses parâmetros em seres humanos (MARANHÃO, QUINTÃO, 1983).

O método acima descrito permite estimar que os participantes deste estudo receberam por dose injetada de ${ }^{14} \mathrm{C}$-oleato de colesterol, 0,26 mGy no intestino grosso inferior, 0,5 mGy no intestino grosso superior, 0,18 mGy na pele, 0,13 mGy na superfície dos ossos e 0,13 mGy no fígado. A dose recebida pelos pulmões, coração, ovários ou testículo é desprezível. Em conformidade com as normas de proteção radiológica (Comissão Nacional de Energia Nuclear, 1988), este valor é muito inferior ao máximo permitido. A dose de radiação induzida pela injeção dos radioisótopos é menor que a obtida com a maioria dos procedimentos radiológicos, sendo cerca de 10 
vezes menor que a dose induzida por uma radiografia de crânio (ALTMAN, 1974).

\subsubsection{Análise dos Dados Cinéticos}

As cinéticas dos triglicérides e do éster de colesterol radioativos fornecem informações distintas. A remoção plasmática dos triglicérides da emulsão reflete o processo de lipólise dos quilomícrons artificiais, enquanto que remoção do éster de colesterol reflete a remoção do remanescente pelo fígado.

As contagens de radioatividade obtidas nas amostras de plasma dos pacientes nos tempos avaliados durante 60 minutos, foram utilizadas para a determinação das curvas de decaimento plasmático e cálculo dos parâmetros cinéticos dos componentes lipídicos radioativos da nanoemulsão, por meio de análise compartimental, com a utilização de um programa computacional desenvolvido para análise de cinética de nanoemulsões por Mesquita, C.H., do Instituto de Pesquisas Energéticas e Nucleares da Universidade de São Paulo, São Paulo, programa AnaComp versão 4.1 (MESQUITA, 1994).

No modelo utilizado (figura 1), a cinética da nanoemulsão foi avaliada por avaliações isoladas das remoções plasmáticas de seus componentes lipídicos radioativos, pelo fato dos mesmos apresentarem cinéticas 
diferentes. Assim como no metabolismo dos quilomícrons naturais, os triglicérides da nanoemulsão são hidrolisados durante o metabolismo, enquanto que o oleato de colesterol permanece no interior da partícula até a captação da mesma pelo fígado.

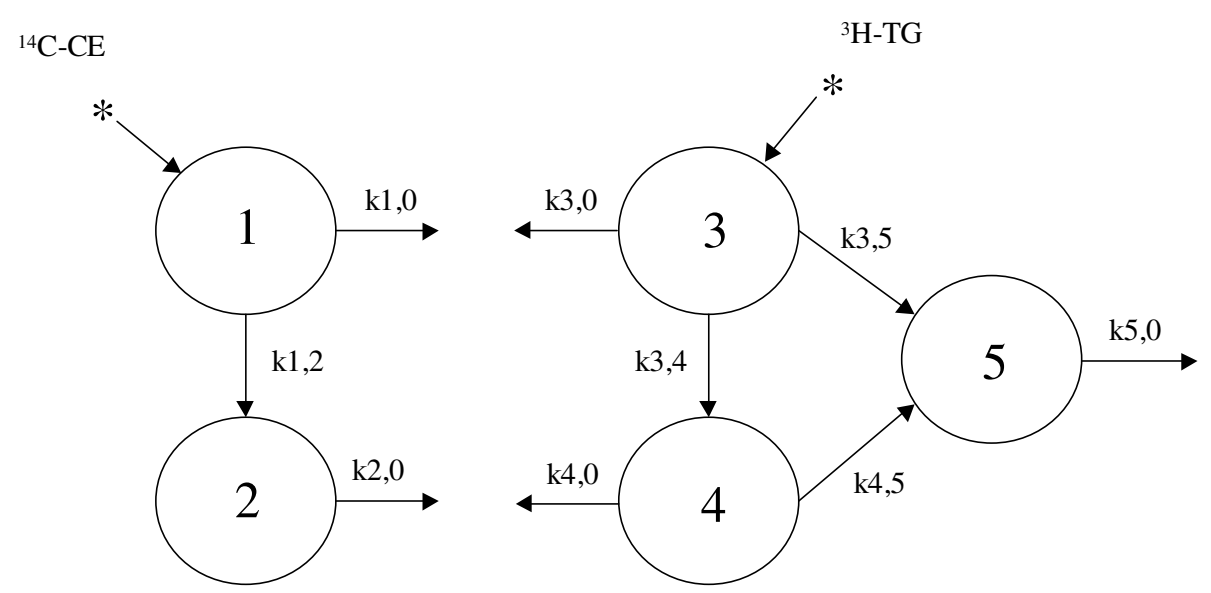

Figura 1 - Modelo compartimental adotado para análise para de cinética plasmática dos quilomícrons artificiais (MESQUITA, 1994)

A curva de remoção plasmática do ${ }^{14} \mathrm{C}$-colesterol esterificado $\left({ }^{14} \mathrm{C}-\mathrm{CE}\right)$ reflete a cinética do colesterol esterificado e apresenta um perfil biexponencial com um rápido decaimento inicial seguido de outro mais lento. Esse perfil levou à adoção de um modelo com dois compartimentos que representam o colesterol esterificado dos quilomícrons artificiais no espaço intravascular, tal como foi injetado (compartimento 1) ou na partícula remanescente, resultante do processo de lipólise (compartimento 2).

A curva de remoção plasmática dos ${ }^{3} \mathrm{H}$-triglicérides $\left({ }^{3} \mathrm{H}\right.$-TG) representa a cinética das moléculas de triglicérides. Embora essa curva 
apresente as mesmas características da curva de remoção do ${ }^{14} \mathrm{C}-\mathrm{CE}$, o seu decaimento é mais rápido devido à ação da LLP. A cinética do ${ }^{3} \mathrm{H}-\mathrm{TG}$ é representada por três compartimentos: os triglicérides na partícula, tal como foi injetada na circulação sanguínea (compartimento 3), as partículas remanescentes (compartimento 4) e os ácidos graxos livres, derivados da hidrólise dos triglicérides (compartimento 5).

A partir desse modelo e com base no método dos mínimos quadrados não linear, foram calculadas as taxas fracionais de transferência $(k)$ dos lípides marcados entre os compartimentos ou para o espaço extravascular.

Os compartimentos e as taxas fracionais de transferência $(k)$ do modelo adotado neste estudo são definidos como:

\subsubsection{Análise da cinética do éster de colesterol marcado com ${ }^{14} \mathrm{C}$ (EC- $\left.{ }^{14} \mathrm{C}\right)$ :}

- o compartimento $\mathrm{n}^{\circ} 1$ representa a emulsão marcada com EC- ${ }^{14} \mathrm{C}$, introduzida no espaço intravascular;

- o k1,0 representa a fração da emulsão que é retirada do compartimento plasmático por meio de via não específica; 
- o k1,2 representa a fração da emulsão que sofre a ação da LLP, perdendo triglicérides e se transformando em uma partícula menor, o remanescente de quilomícron, o qual é representado pelo compartimento $\mathrm{n}^{\circ}$ 2

- o compartimento $n^{\circ} 2$ representa o remanescente de quilomícron, resultante da ação lipolítica;

- o k2,0 representa a fração de remanescente de quilomícron que é removida do compartimento plasmático, por meio de captação principalmente hepática.

\subsubsection{Análise da cinética dos triglicérides marcados $\operatorname{com}^{3} \mathrm{H}\left(\mathrm{TG}-{ }^{3} \mathrm{H}\right)$ :}

- o compartimento $n^{\circ} 3$ representa a emulsão marcada com ${ }^{3} \mathrm{H}-\mathrm{TG}$, injetada na circulação sanguínea;

- o k3,0 representa a fração da emulsão que é removida do compartimento plasmático por meio de via não específica;

- o k3,4 representa a fração da emulsão que sofre a ação da LLP, perde triglicérides se transforma no remanescente de quilomícron;

- o compartimento $\mathrm{n}^{\circ} 4$ representa o remanescente de quilomícron; 
- o k3,5 representa a fração de ácidos graxos livres formada a partir da hidrólise dos triglicérides, pela ação da LLP sobre os quilomícrons;

- o k4,5 representa a fração de ácidos graxos livres formada a partir da hidrólise dos triglicérides, pela ação da LLP sobre os quilomícrons;

- o k4,0 representa a fração de remanescente captada principalmente pelo fígado.

- o k5,0 representa o desaparecimento dos ácidos graxos livres do compartimento extravascular.

Para representar a remoção das partículas foram utilizados os parâmetros denominados taxas fracionais de remoção (TFR), em $\min ^{-1}$, dos lípides marcados, calculados pela média ponderada das respectivas taxas fracionais de transferência $(k)$.

\subsubsection{Atividade da Lípase Lipoprotéica (LLP)}

Para a avaliação da atividade da LLP, foram utilizadas como substrato emulsões lipídicas artificiais obtidas conforme descrito anteriormente, marcadas apenas com ${ }^{3} \mathrm{H}$-trioleína. A avaliação foi realizada 15 minutos após a última coleta dos estudos cinéticos, quando foi colhida uma amostra de sangue para avaliar a radioatividade residual no plasma, a qual, quando constatada, foi subtraída dos resultados. 
Os pacientes receberam uma injeção endovenosa de heparina sódica (100 U/kg) e após 10 minutos foram colhidas amostras de sangue $(20 \mathrm{ml})$ em tubos contendo heparina (50ul) (GIANINNI et al., 1970; SULTAN et al., 1990; VINAGRE et al.,2000). As amostras foram imediatamente colocadas em banho de gelo e centrifugadas em centrífuga refrigerada Sorvall (modelo RT7, Wilmington, EUA), a $2.700 \mathrm{rpm}, 4^{\circ} \mathrm{C}$, durante 10 minutos.

Para a determinação da atividade lipolítica total, alíquotas de 500 ul de plasma dos participantes foram incubadas com 25 ul das emulsões de quilomícrons artificiais, em Banho-Maria a $37^{\circ} \mathrm{C}$, sob agitação, em tempos pré-estabelecidos (5, 15, 30, 45, 60, 120 e 180 minutos). Após cada tempo, as amostras foram retiradas do Banho-Maria, colocadas imediatamente em banho de gelo e submetidas à extração de lípides pelo método de Folch, com clorofórmio:metanol:água destilada (5mL: 2,5 mL:2,5mL). Após 12 horas a $4^{\circ} \mathrm{C}$, os infranadantes das amostras foram aspirados, secos sob fluxo de nitrogênio, ressuspendidos com 300 uL de clorofórmio:metanol (2:1) e aplicados em placas de cromatografia em camada delgada que continham sílica gel 60 H como fase estacionária.

Após a aplicação, as placas foram colocadas em sistema solvente, constituído de n-hexano/éter etílico/ácido acético glacial (70 ml: $30 \mathrm{ml}$ : 1,0 ml), para separação das frações lipídicas. Será determinada a radioatividade presente na fração correspondente aos triglicérides, em solução cintiladora descrita anteriormente, utilizando-se um contador Beta (Packard modelo 1660 TR, EUA). Através das contagens obtidas, foram calculadas as percentagens de triglicérides ainda restantes na emulsão em cada tempo de 
incubação estudado. Foram traçadas as curvas de hidrólise dos triglicérides radioativos da emulsão e calculadas as áreas sob as curvas (ASC).

\subsubsection{Determinações Bioquímicas}

A determinação dos níveis plasmáticos de triglicérides foi realizada através de método enzimático (Merck S.A. Indústrias Químicas, Rio de Janeiro, Brasil).

O colesterol total foi determinado por método colorimétrico enzimático (Chod-Pap, Merck S.A. Indústrias Químicas, Rio de Janeiro, Brasil). O colesterol de HDL foi determinado pelo mesmo método utilizado para o colesterol total, após precipitação química das lipoproteínas que contêm apolipoproteína B, utilizando-se reagente precipitante constituído por cloreto de magnésio e ácido fosfotungstico. O valor do colesterol de LDL foi obtido pela diferença entre o colesterol total e a somatória do colesterol de HDL e colesterol de VLDL. O colesterol de VLDL foi calculado através da divisão dos níveis plasmáticos de triglicérides por 5 .

Colesterol de LDL= [colesterol total $-(\mathrm{HDL}-\mathrm{C}+\mathrm{VLDL}-\mathrm{C})]$

Colesterol de VLDL= triglicérides $/ 5$ 


\subsubsection{Avaliação da "Transferência de Lípides da Nanoemulsão LDE para a HDL"}

A transferência de lípides da LDE para a HDL foi avaliada conforme descrito anteriormente (LO PRETE et al., 2009; PUK et al., 2009). Uma alíquota de $200 \mu \mathrm{L}$ de plasma dos participantes foi incubada com $50 \mu \mathrm{L}$ da nanoemulsão LDE marcada com os lípides radioativos (oleato de colesterol${ }^{14} \mathrm{C}$, trioleína- ${ }^{3} \mathrm{H}$, colesterol- ${ }^{3} \mathrm{H}$ e fosfolípides $-{ }^{14} \mathrm{C}$ ), a $37^{\circ} \mathrm{C}$, sob agitação, durante 1 hora. Após esse procedimento, foram adicionados $250 \mu \mathrm{L}$ de reagente precipitante $\left(0,2 \%\right.$ Dextran/0,3 $\left.\mathrm{mol} / \mathrm{L} \mathrm{MgCl}_{2}\right)$ seguida de agitação por 30 segundos e centrifugação por 10 minutos, a 3000 rotações por minuto. O infranadante, contendo a nanoemulsão LDE e as lipoproteínas plasmáticas que contém apo B, VLDL e LDL foi desprezado. O sobrenadante, contendo a HDL, foi submetido à contagem da radioatividade presente, que corresponde à transferência dos lípides radioativos da LDE para a HDL do indivíduo. Foi calculada a percentagem de transferência de cada um dos lípides radioativos, considerando como 100\%, a radioatividade total utilizada na incubação. A quantificação dos lípides transferidos da LDE para a HDL plasmática foi expressa como percentegem (\%) em relação à radioatividade total incubada. 


\subsubsection{Determinação do Diâmetro da HDL}

O tamanho da HDL foi mensurado por espalhamento de luz (light scattering) utilizando o equipamento Laser Light Scattering (ZetaPALMS, Brookhaven Instr. Corp.) (LIMA, MARANHÃO, 2004).

Foram adicionados $500 \mu \mathrm{L}$ polietilenoglicol 8000 (PEG) a 40\% (p/v) a uma alíquota de $500 \mu \mathrm{L}$ de plasma, separada de amostra de sangue colhida com EDTA. Após agitação por 30 segundos, a mistura foi centrifugada por 10 minutos, $3000 \mathrm{rpm}$. Foram retirados $500 \mu \mathrm{L}$ do sobrenadante, ao qual foram adicionados $1500 \mu$ Lde solução salina 1:10 (v/v) e em seguida passaram em filtro Millipore 0,22 $\mu \mathrm{m}$ de diâmetro. O diâmetro das partículas (nm) em solução foi mensurado pela luz espalhada, coletada em um ângulo de 90 e expressos pelo resultado médio obtido em 5 corridas.

\subsubsection{Análise Estatística}

Inicialmente todas as variáveis foram analisadas descritivamente. Para as variáveis quantitativas esta análise foi feita através da observação dos valores mínimos e máximos, e do cálculo de médias, 
desvios-padrão e mediana. Para as variáveis qualitativas calculou-se freqüências absolutas e relativas.

Para a comparação de médias dos três grupos foi utilizada a Análise de Variância a um fator (ANOVA) (ROSNER, 1986), com as comparações múltiplas realizadas através do teste de Bonferroni. Quando a suposição de normalidade foi rejeitada foi utilizado o teste não-paramétrico de Kruskal-Wallis (ROSNER, 1986) com as comparações múltiplas realizadas através do teste de Dunn.

Para se testar a homogeneidade entre as proporções foi utilizado o teste qui-quadrado (ROSNER, 1986).

Para o estudo de correlações foi utilizado o coeficiente de correlação de Pearson (ROSNER, 1986)

O nível de significância utilizado para os testes foi de $5 \%$. 
RESULTADOS 


\subsection{RESULTADOS}

\subsection{Características clínicas dos grupos estudados}

Como observado na Tabela 1, os grupos vegano, ovolacto-vegetariano e onívoro foram pareados por idade, sexo e índice de massa corpórea.

Tabela 1 - Características clínicas dos grupos vegano, ovolacto-vegetariano e onívoro

\begin{tabular}{lccc}
\hline Parâmetros & $\begin{array}{c}\text { Vegano } \\
(\mathbf{n = 2 1})\end{array}$ & $\begin{array}{c}\text { Ovolacto-vegetariano } \\
(\mathbf{n}=\mathbf{1 8})\end{array}$ & $\begin{array}{c}\text { Onívoros } \\
(\mathbf{n}=\mathbf{2 9})\end{array}$ \\
\hline Sexo(M/F) & $11 / 10$ & $8 / 10$ & $17 / 12$ \\
Idade (anos) & $35 \pm 10$ & $35 \pm 7$ & $37 \pm 9$ \\
IMC $\left(\mathrm{Kg} / \mathrm{m}^{2}\right)$ & $22,7 \pm 2,2$ & $23 \pm 1,6$ & $23,5 \pm 1,2$ \\
$\mathrm{AF}$ moderada (\%) & 52 & 66 & 45 \\
& & & \\
\hline $\begin{array}{l}\text { Dados expressos em média } \pm \text { desvio padrão. Abreviaturas: IMC=Índice de } \\
\text { massa corpórea; AF= atividade física }\end{array}$
\end{tabular}




\subsection{Estimativa de ingestão de energia e macronutrientes entre veganos, ovolacto-vegetarianos e onívoros}

Como observado na Tabela 2, indivíduos veganos consomem diariamente uma menor quantidade de calorias totais quando comparado aos ovolacto-vegetarianos $(p<0,001)$ e onívoros $(p<0,001)$. Entretanto, $o$ consumo de carboidratos foi maior pelos indivíduos veganos comparado aos ovolacto-vegetarianos $(p<0,05)$ e onívoros $(p<0,05)$. Em relação ao consumo de proteínas, gordura total, gordura saturada, fibras e colesterol, também foram encontradas diferenças entre os grupos. Indivíduos veganos consumiam uma menor quantidade quando comparado aos ovolactovegetarianos $(p=0,05 ; p<0,001 ; p<0,001 ; p<0,001 ; p<0,05$ : respectivamente) e onívoros ( $p<0,001 ; p<0,001 ; p<0,001 ; p<0,001 ; p<0,05$ : respectivamente). Quando realizada a comparação entre esses dois grupos, o consumo foi menor no grupo ovolacto-vegetariano de proteínas $(p=0,02)$, gordura total $(p=0,01)$, gordura saturada $(p<0,001)$, fibras $(p<0,001)$ e colesterol $(p<0,05)$ do que em onívoros.

Em relação à gordura poliinsaturada, indivíduos veganos consumiam uma maior quantidade quando comparado aos ovolacto-vegetarianos $(p<0,001)$ e onívoros $(p<0,001)$. Já o consumo de gordura monoinsaturada foi maior no grupo ovolacto-vegetariano quando comparada ao grupo vegano $(p=0,01)$ e onívoro $(p<0,001)$ 
Tabela 2 - Estimativa de ingestão de energia e macronutrientes entre os grupos estudados

\begin{tabular}{|c|c|c|c|}
\hline Alimentos & $\begin{array}{l}\text { Vegano } \\
(n=21)\end{array}$ & $\begin{array}{c}\text { Ovolacto-vegetariano } \\
(n=18)\end{array}$ & $\begin{array}{l}\text { Onívoro } \\
(n=29)\end{array}$ \\
\hline Calorias Totais (Kg/cal) & $1495 \pm 113^{\mathrm{ce}}$ & $1900 \pm 69$ & $1947 \pm 140$ \\
\hline Carboidratos (g) & $61,5 \pm 1,6^{\mathrm{ad}}$ & $54,2 \pm 1,5$ & $51,9 \pm 2,2$ \\
\hline Proteínas (g) & $14,3 \pm 3,6^{\text {ae }}$ & $15 \pm 0,5^{d}$ & $15,6 \pm 0,9$ \\
\hline Gordura Total (g) & $24,9 \pm 1^{\mathrm{ce}}$ & $30,6 \pm 1,6^{\dagger}$ & $32,4 \pm 2,6$ \\
\hline Gordura Saturada (g) & $4,7 \pm 0,4^{\text {ce }}$ & $7,7 \pm 0,4^{\mathrm{e}}$ & $12,3 \pm 1,0$ \\
\hline Gordura poliinsaturada (g) & $7,6 \pm 0,5^{\mathrm{ce}}$ & $5,7 \pm 0,6$ & $5,6 \pm 0,9$ \\
\hline Gordura monoinsaturada (g) & $12,5 \pm 0,9$ & $13,9 \pm 1,1^{\text {be }}$ & $12,4 \pm 1,6$ \\
\hline Fibras (g) & $58,4 \pm 1,8^{\text {ce }}$ & $43,1 \pm 2,5^{\mathrm{e}}$ & $23,9 \pm 3,2$ \\
\hline Colesterol (mg) & $51,2 \pm 4,4^{\mathrm{ad}}$ & $151,1 \pm 8,4^{d}$ & $249 \pm 23,6$ \\
\hline \multicolumn{4}{|c|}{$\begin{array}{l}\text { Dados expressos em média } \pm \text { desvio padrão. } \\
{ }^{a} p<0,05 \text { quando comparado ao grupo ovolacto-vegetariano } \\
{ }_{\mathrm{b}} \mathrm{p}<0,01 \text { quando comparado ao grupo ovolacto-vegetariano } \\
{ }_{\mathrm{c}} \mathrm{p}<0,001 \text { quando comparado ao grupo ovolacto-vegetariano } \\
\mathrm{d}_{\mathrm{p}}<0,05 \text { quando comparado ao grupo onívoro. } \\
{ }_{\mathrm{e}} \mathrm{p}<0,001 \text { quando comparado ao grupo onívoro. } \\
\mathrm{f}_{\mathrm{p}}<0,01 \text { quando comparado ao grupo onívoro. }\end{array}$} \\
\hline
\end{tabular}


4.3 Taxa fracional de remoção do éster de colesterol (TFR-EC- ${ }^{14} \mathrm{C}$ ) e dos triglicérides (TFR-TG- ${ }^{3} \mathrm{H}$ ), taxa de lipólise e atividade da lipase lipoprotéica

Como observado na figura 2 , a remoção plasmática dos remanescentes dos quilomícrons artificiais representada pela taxa fracional de éster de colesterol (TFR-CE- ${ }^{14} \mathrm{C}$ ) está aumentada no grupo vegano $(p<0,05)$ e ovolacto-vegetariano $(p<0,05)($ TABELA 3$)$.

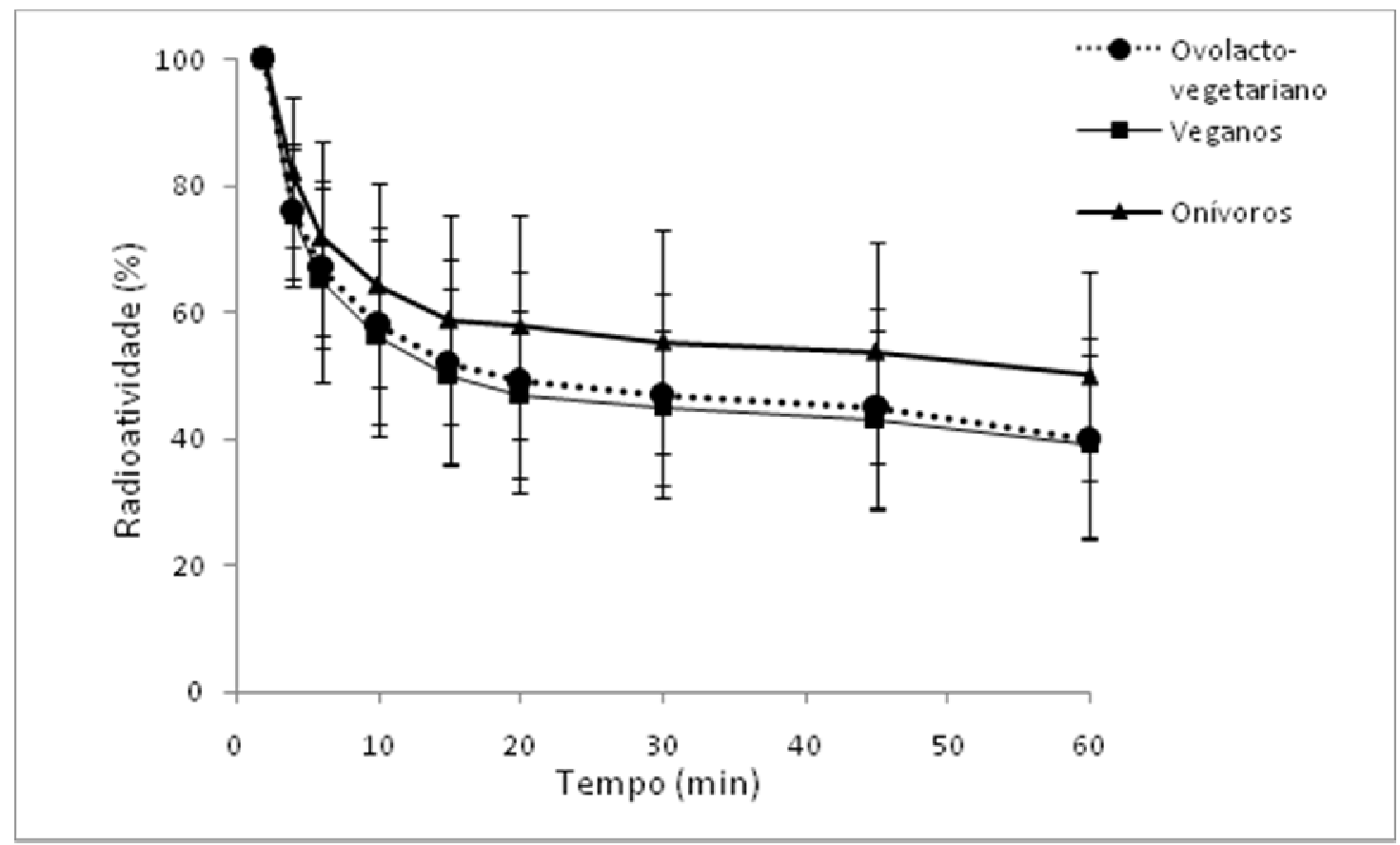

FIGURA 2. Curvas de remoção plasmática do éster de colesterol- ${ }^{14} \mathrm{C}$ dos quilomícrons artificiais nos grupos vegano, ovolacto-vegetariano e onívoro. 
Ao comparar a TFR-TG- ${ }^{3} \mathrm{H}$ nos grupos estudados, vegano, ovolactovegetariano e onívoro, não foram constatadas diferenças significativas $(p=0,428)$ (FIGURA 3 e TABELA 3).

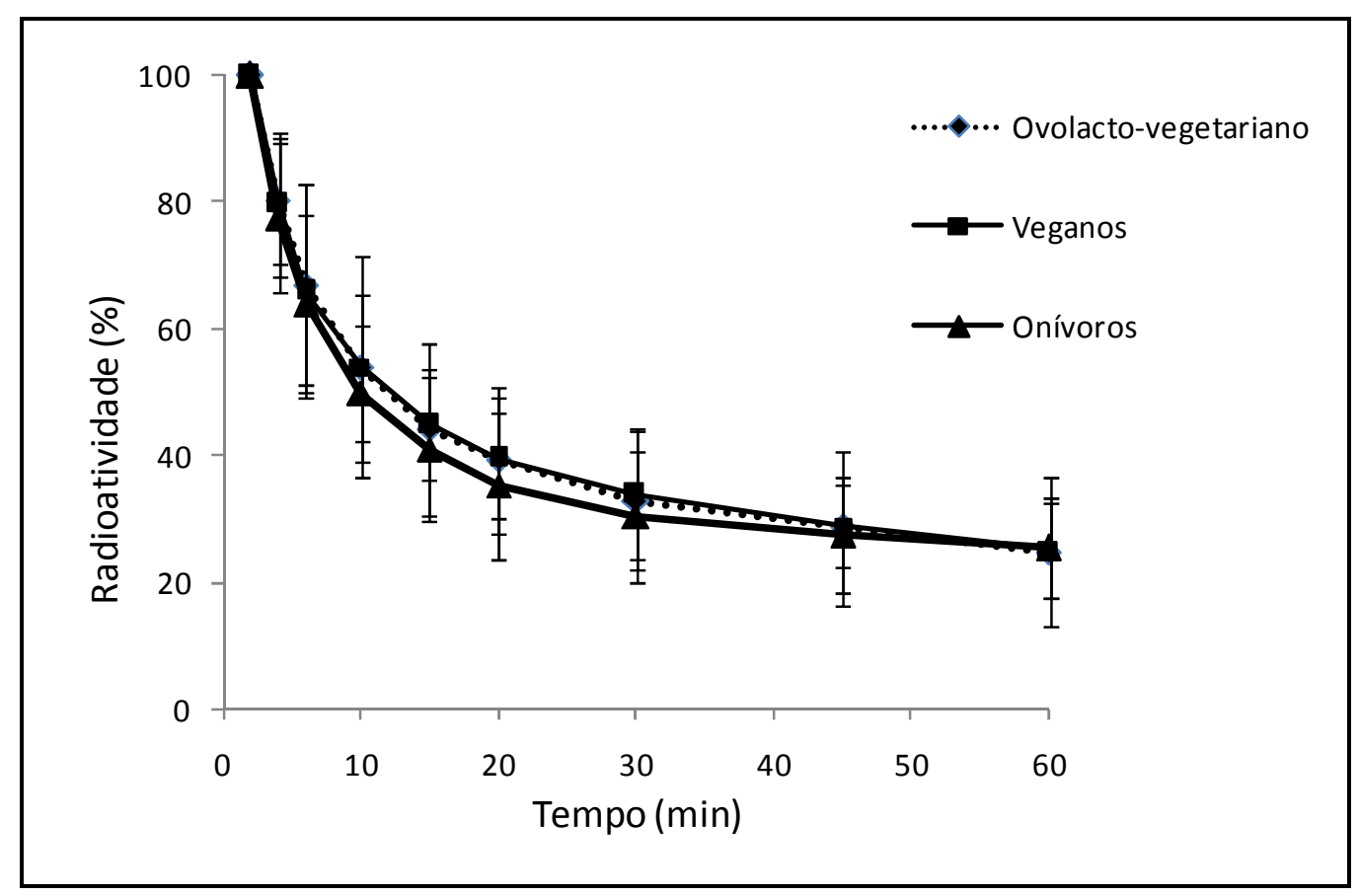

FIGURA 3. Curvas de remoção plasmática dos triglicérides- ${ }^{3} \mathrm{H}$ dos quilomícrons artificiais nos grupos vegano, ovolacto-vegetariano e onívoro.

Em relação à atividade da lipase lipoprotéica e a taxa de lipólise, não houve diferença siginificativa entre os grupos estudados (TABELA 3). 
Tabela 3 - Taxa fracional de remoção do éster de colesterol (TFR-EC- $\left.{ }^{14} \mathrm{C}\right)$ e dos triglicérides (TFR-TG- ${ }^{3} \mathrm{H}$ ), em $\mathrm{min}^{-1}$ e atividade da lipase lipoprotéica (LLP) nos grupos estudados

\begin{tabular}{lccc}
\hline Parâmetros & $\begin{array}{c}\text { Vegano } \\
(\mathbf{n}=21)\end{array}$ & $\begin{array}{c}\text { Ovolacto-vegetariano } \\
(\mathbf{n}=18)\end{array}$ & $\begin{array}{c}\text { Onívoro } \\
(\mathbf{n}=\mathbf{2 8})\end{array}$ \\
\hline TFR-EC- ${ }^{14} \mathrm{C}$ & $0,016 \pm 0,012^{\mathrm{a}}$ & $0,017 \pm 0,018^{\mathrm{a}}$ & $0,003 \pm 0,003$ \\
TFR-TG- ${ }^{3} \mathrm{H}$ & $0,024 \pm 0,014$ & $0,030 \pm 0,016$ & $0,030 \pm 0,016$ \\
Lipólise & $0,018 \pm 0,023$ & $0,023 \pm 0,023$ & $0,022 \pm 0,024$ \\
Atividade LLP & $8598 \pm 2332$ & $8755 \pm 3396$ & $7178 \pm 1803$ \\
\hline
\end{tabular}

Dados expressos em média \pm desvio padrão.

${ }^{a} p<0,05$ quando comparado ao grupo onívoro

\subsection{Determinações bioquímicas}

Observa-se na Tabela 4, os valores das concentrações plasmáticas dos lipídeos e glicose dos grupos estudados.

Houve diferença entre os níveis séricos de colesterol total do grupo vegano, quando comparado ao grupo ovolacto-vegetariano $(p<0,05)$ e ao onívoro $(p=0,005)$.

Com relação aos resultados das concentrações de LDL-C, houve uma diferença significativa apenas quando comparado o grupo vegano ao grupo onívoro $(p<0,05)$. O mesmo foi observado com as concentrações plasmáticas de glicose $(\mathrm{p}=0,01)$. 
Não houve diferença significativa nos níveis séricos de triglicérides entre os grupos vegano, ovolacto-vegetariano e onívoro $(p=0,229)$. $O$ mesmo ocorrendo com a HDL $(p=0,388)$ e VLDL $(p=0,122)$.

Tabela 4 - Concentrações plasmáticas dos lipídeos e glicose dos grupos estudados

\begin{tabular}{|c|c|c|c|}
\hline Parâmetros & $\begin{array}{l}\text { Vegano } \\
(\mathrm{n}=21)\end{array}$ & $\begin{array}{c}\text { Ovolacto-vegetariano } \\
(n=18)\end{array}$ & $\begin{array}{c}\text { Onívoro } \\
(\mathrm{n}=29)\end{array}$ \\
\hline \multicolumn{4}{|c|}{ Colesterol (mg/dL) } \\
\hline Total & $140 \pm 33^{\mathrm{bc}}$ & $167 \pm 27$ & $168 \pm 27$ \\
\hline LDL & $83 \pm 32^{a}$ & $103 \pm 26$ & $105 \pm 27$ \\
\hline HDL & $41 \pm 9$ & $42 \pm 8$ & $45 \pm 12$ \\
\hline VLDL & $15 \pm 8$ & $22 \pm 9$ & $24 \pm 11$ \\
\hline Triglicérides & $82 \pm 38$ & $104 \pm 27$ & $88 \pm 44$ \\
\hline Glicose & $70 \pm 17^{\mathrm{b}}$ & $74 \pm 18$ & $84 \pm 7$ \\
\hline \multicolumn{4}{|c|}{$\begin{array}{l}\text { Dados expressos em média } \pm \text { desvio padrão. } L D L=\text { lipoproteína de baix } \\
\text { densidade; } H D L=\text { lipoproteína de alta densidade; } V L D L=\text { lipoproteína d } \\
\text { densidade muito baixa densidade }\end{array}$} \\
\hline \multicolumn{4}{|c|}{${ }^{\mathrm{a}} \mathrm{p}<0,05$ quando comparado ao grupo onívoro } \\
\hline \multicolumn{4}{|c|}{${ }^{b} p<0,01$ quando comparado ao grupo onívoro } \\
\hline${ }^{c} p<0,05$ quar & cado ao $\mathrm{g}$ & ovolacto-vegetariano & \\
\hline
\end{tabular}


4.5 Taxa de transferência de éster de colesterol, colesterol livre, triglicerídeos e fosfolipídeos da LDE para HDL e determinação do diâmetro da HDL.

$\mathrm{Na}$ Tabela 5 observa-se os valores das taxas de transferência de éster de colesterol, colesterol livre, triglicerídeos e fosfolipídeos da LDE para HDL e determinação do diâmetro da HDL dos três grupos estudados.

Não houve diferença nas taxas de transferência do ${ }^{3} \mathrm{H}$-éster de colesterol $(p=0,079),{ }^{14} \mathrm{C}$-colesterol livre $(p=0,683)$, triglicerídeos $(p=0,473)$ e fosfolipídeos $(p=0,689)$ entre os grupos estudados. O mesmo ocorreu com o tamanho das partículas de HDL, que foi semelhante entre veganos, ovolacto-vegetarianos e onívoros ( $p=0,136)$.

Tabela 5 - Taxa de transferência (\%) do éster de colesterol, colesterol livre, triglicerídeos e fosfolípideos da emulsão rica em colesterol (LDE) para a HDL e diâmetro das partículas de HDL $(\mathrm{nm})$ nos grupos estudados

\begin{tabular}{lccc}
\hline Taxas de transferência & $\begin{array}{c}\text { Vegano } \\
(\mathbf{n = 1 0})\end{array}$ & $\begin{array}{c}\text { Ovolacto-vegetariano } \\
(\mathbf{n = 1 3})\end{array}$ & $\begin{array}{c}\text { Onívoro } \\
(\mathbf{n}=\mathbf{1 4})\end{array}$ \\
\hline${ }^{3} \mathrm{H}$-éster de colesterol (\%) & $2,8 \pm 0,6$ & $2,9 \pm 0,8$ & $3,5 \pm 1,5$ \\
${ }^{14} \mathrm{C}$-colesterol (\%) & $7,3 \pm 2,5$ & $8,0 \pm 1,8$ & $7,5 \pm 2,7$ \\
${ }^{3} \mathrm{H}$-triglicerídeos (\%) & $4,4 \pm 2,4$ & $4,53 \pm 0,56$ & $3,6 \pm 2,1$ \\
${ }^{14}$-fosfolipídeos (\%) & $19,8 \pm 2,7$ & $20,7 \pm 2,0$ & $20,6 \pm 5,0$ \\
Tamanho HDL (nm) & $9,3 \pm 1,5$ & $9,9 \pm 1,5$ & $9,3 \pm 1,4$ \\
\hline $\begin{array}{l}\text { Dados expressos em média } \pm \text { desvio padrão. HDL= lipoproteína de alta } \\
\text { densidade }\end{array}$ &
\end{tabular}


4.6 Correlações entre taxa fracional de éster de colesterol (TFR-EC- ${ }^{14} \mathrm{C}$ ) e o consumo de carboidratos, proteínas, gordura saturada, fibras e colesterol

Como demonstrado na Tabela 6, a taxa fracional de éster de colesterol se correlacionou positivamente com o consumo de fibras $(r=0.360 ; p=0,021)$, carboidratos $(r=0,329 ; p=0,021)$ e proteínas $(r=-0,328 ; p=0,036)$ e inversamente com o consumo de gordura saturada $(r=-0,320 ; p=0,042)$ e colesterol $(r=-0,324 ; p=0,039)$. Não foram encontradas correlações entre o consumo de calorias totais e dos demais nutrientes e a taxa fracional de éster de colesterol. 
Tabela 6 - Correlação entre a taxa fracional de éster de colesterol e o consumo de calorias totais, carboidrato, proteína, gordura total, gordura saturada, gordura poliinsaturada, gordura monoinsaturada, fibras e colesterol

\begin{tabular}{lcc}
\hline Variáveis & \multicolumn{1}{c}{ Taxa fracional de éster de colesterol } \\
\hline Calorias totais (Kg/cal) & $r$ & $p$ \\
Carboidratos (g) & $-0,189$ & 0,238 \\
Proteínas (g) & 0,359 & 0,021 \\
Gordura Total (g) & $-0,328$ & 0,036 \\
Gordura Saturada (g) & $-0,295$ & 0,061 \\
Gordura Poliinsaturada (g) & $-0,324$ & 0,039 \\
Gordura Monoinsaturada (g) & 0,172 & 0,284 \\
Fibras (g) & $-0,085$ & 0,599 \\
Colesterol (mg) & 0,360 & 0,021 \\
\end{tabular}

Dados expressos como coeficiente de correlação (r) de Pearson 
Figura 4 - Correlações entre taxa fracional de éster de colesterol (TFREC- ${ }^{14} \mathrm{C}$ ) e o consumo de carboidratos, proteínas, gordura saturada, fibras e colesterol (continua)
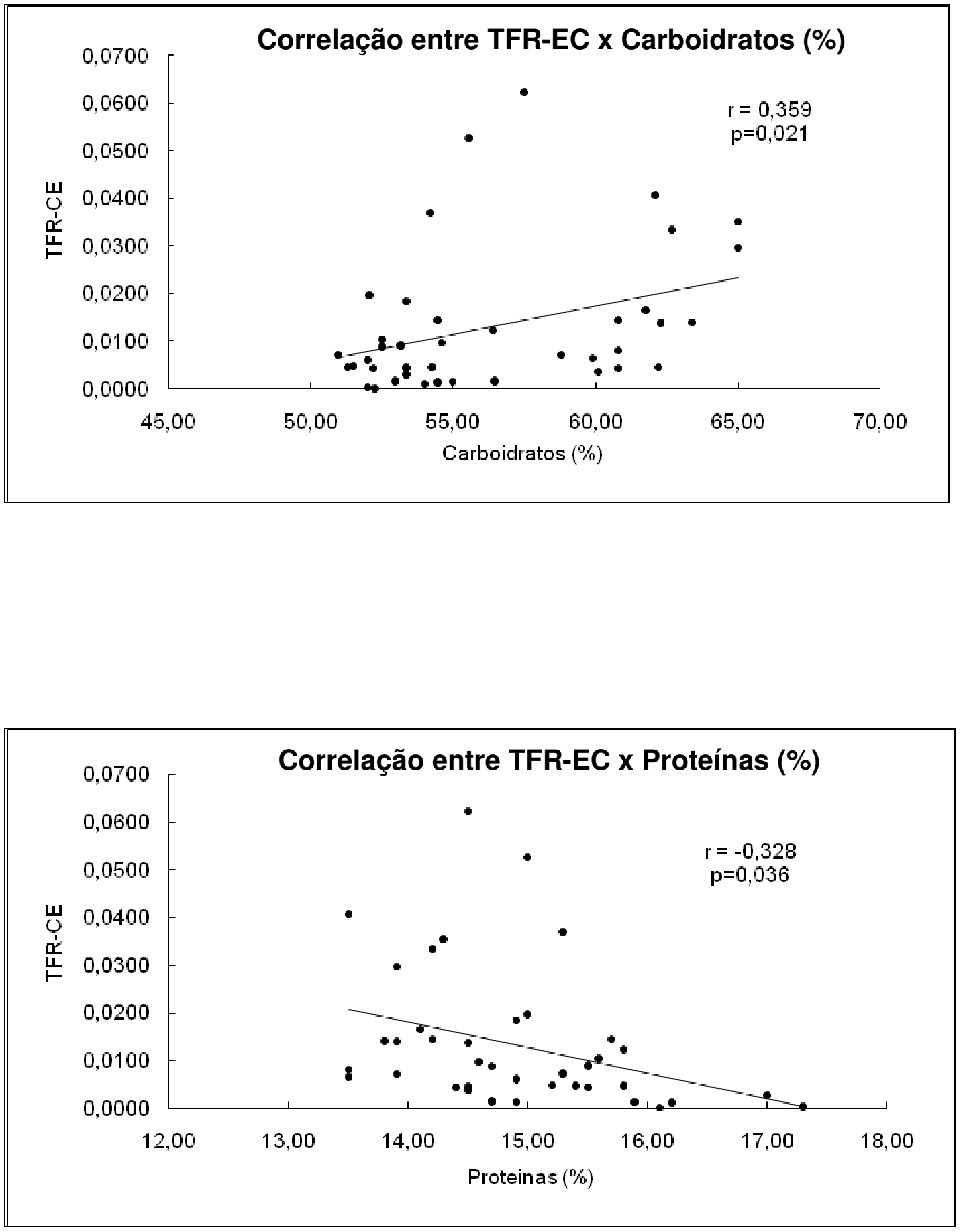
Figura 4 - Correlações entre taxa fracional de éster de colesterol (TFREC- ${ }^{14} \mathrm{C}$ ) e o consumo de carboidratos, proteínas, gordura saturada, fibras e colesterol (continua)
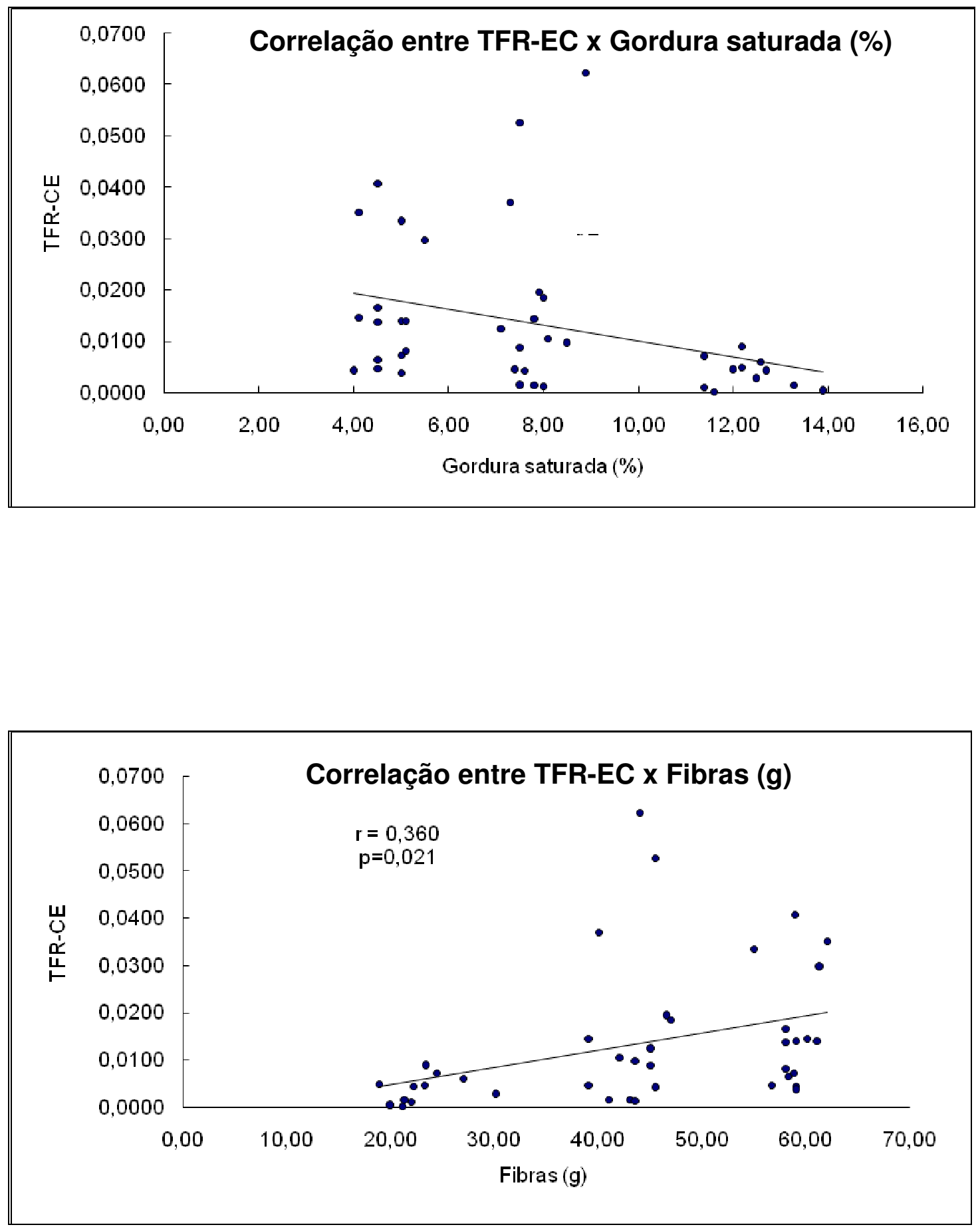
Figura 4 - Correlações entre taxa fracional de éster de colesterol (TFREC- ${ }^{14} \mathrm{C}$ ) e o consumo de carboidratos, proteínas, gordura saturada, fibras e colesterol. (conclusão)

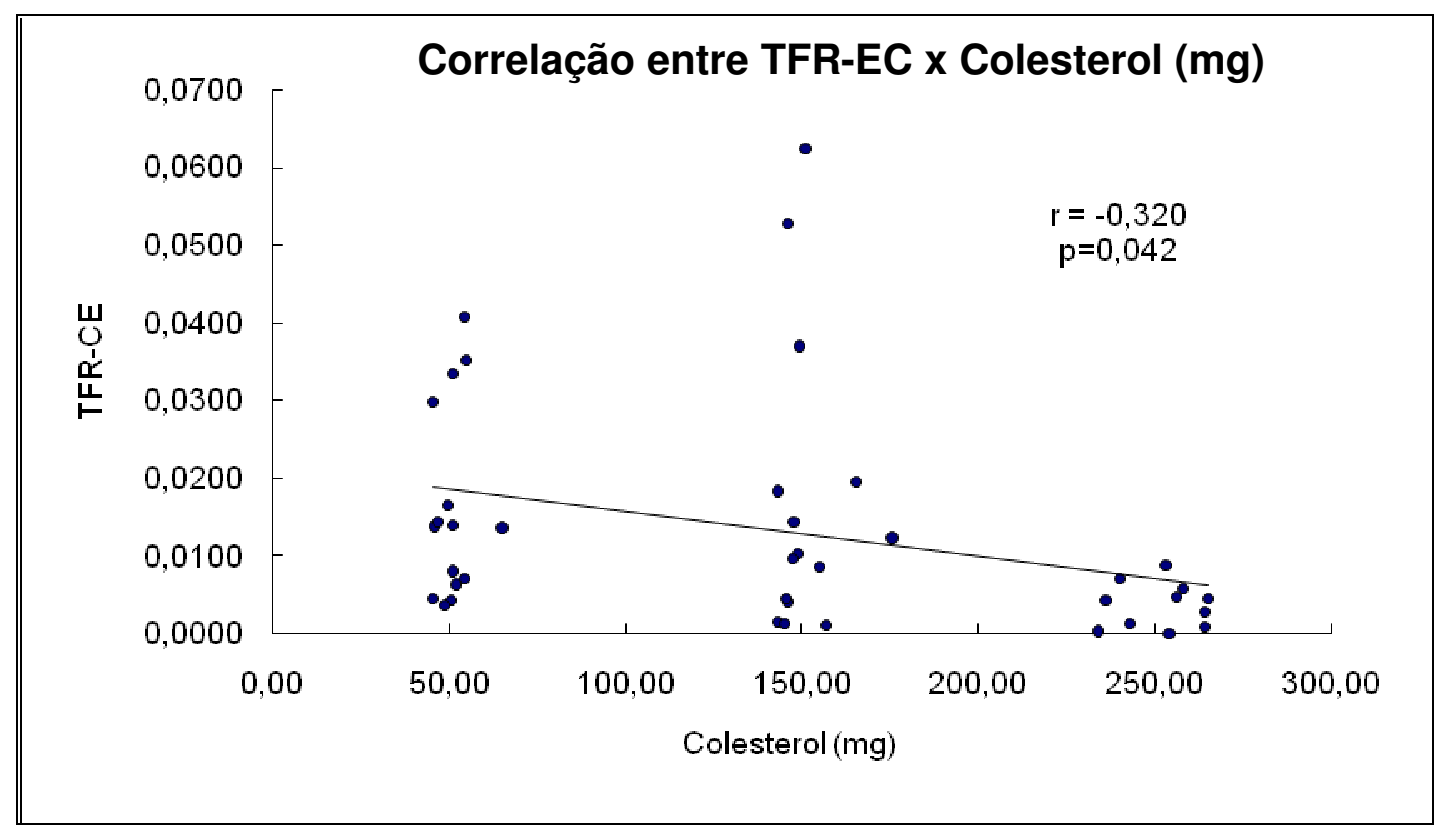


DISCUSSÃO 


\section{DISCUSSÃO}

No presente estudo, indivíduos veganos e ovolacto-vegetarianos apresentaram remoção mais rápida do éster de colesterol da emulsão de quilomícrons, quando comparados aos onívoros. Portanto, a dieta vegetariana leva a mecanismos mais eficientes de remoção dos remanescentes resultantes da lipólise dos quilomícrons que os indivíduos onívoros.

A remoção deficiente de remanescentes ou o acúmulo de triglicérides pós-prandiais tem sido associada com risco aumentado de desenvolvimento (GROOT et al., 1991; PATSCH et al., 1992; MARANHÃO et al, 1996; PROCTOR et al., 1996 e 2004; SPOSITO et al., 2004a; BANSAL et al., 2007; NORDESTGAARD et al., 2010) e progressão de doença arterial coronária (DAC) (KARPE et al., 1994). Em vários estudos que utilizaram diferentes marcadores de remanescentes como retinil palmitato (WEINTRAUB et al., 1996 ) ou apo B48 (ROCHE et al., 1998a; MEKKI et al., 2002; JACKSON et al., 2005), pacientes com DAC apresentaram acúmulo dos remanescentes marcados. Com a metodologia de emulsões utilizada no presente estudo, uma emulsão semelhante aos quilomícrons com marcação radioativa do éster de colesterol e dos triglicérides é injetada em indivíduos em jejum, para avaliar os processos metabólicos dos quilomícrons na circulação sanguínea (MARANHÃO et al., 1996; VINAGRE et al., 2000; 
CESAR et al., 2006). Em estudo realizado anteriormente com a emulsão (MARANHÃO et al., 1996), foi demonstrado que a remoção tanto do éster de colesterol como dos triglicérides da emulsão estava deficiente em pacientes com DAC, comparando-se com indivíduos sem a doença.

Os remanescentes de quilomícrons podem contribuir com a aterogênese por vários mecanismos (DOI et al., 2000; YU \& MAMO, 2000; ELSEGOOD et al., 2001; KAWAKAMI et al., 2001NAPOLITANO et al., 2001; YU \& COOPER, 2001; BATT et al., 2004; BOTHAM et al., 2005; SANIABADI et al.,1997; KUGIYAMA et al., 1998; KAWASAKI et al., 2000)., sendo que partículas semelhantes a remanescentes foram encontradas em placas ateroscleróticas (PAL et al., 2003). Vários estudos têm demonstrado que a composição dos ácidos graxos da dieta pode influenciar o metabolismo das lipoproteínas pós-prandiais (GRUNDY, 1987; WEINTRAUB et al., 1988; WOOLETT LA et al., 1992; ZAMPELAS et al., 1994; DIETSCHY DK, 1995; ROCHE et al., 1998b; LAMBERT et al., 2000; LAMBERT et al., 2001). Dietas ricas em ácidos graxos poliinsaturados tendem a diminuir a resposta pósprandial comparadas as ricas em ácidos graxos saturados (WEINTRAUB et al., 1988; ZAMPELAS et al., 1994; ROCHE et al., 1998). A composição de ácidos graxos do remanescente de quilomícron constitui um importante fator envolvido em sua captação pelo fígado (LAMBERT et al, 1995; LAMBERT et al., 2000).

Conforme também observado no presente estudo, indivíduos veganos e ovolacto-vegetarianos consomem menos gordura total, gordura saturada e colesterol que indivíduos onívoros (BALL \& BARLLET, 1999; DAVEY et al., 
2003; CRAIG e MANGELS, 2009). Em nosso estudo, o consumo de gordura monoinsaturada foi maior nos indivíduos ovolacto-vegetarianos comparados com veganos e onívoros. Entretanto, veganos não apresentaram maior consumo de gordura monoinsaturada que onívoros, o que também foi observado em outros estudos (KORNSTEINER et al., 2008). Conforme observado em outros estudos (FOKEMMA et al., 2000; ROSELL et al., 2005), o consumo de gordura poliinsaturada foi maior nos veganos comparando-se com os onívoros. Em relação aos veganos e ovolactovegetarianos, também foi observado um maior consumo de gordura poliinsaturada em veganos (ROSELL et al., 2005), ao contrário do que foi observado em outros estudos (TOOHEY et al., 1998; KORNSTEINER et al., 2008), sendo que não houve diferença entre ovolacto-vegetarianos e onívoros, conforme também demonstrado anteriormente (KORNSTEINER et al., 2008).

O aumento da remoção plasmática de remanescentes, indicado pela maior taxa de remoção do éster de colesterol da emulsão, nos dois grupos de vegetarianos, no presente estudo, pode estar relacionado ao menor consumo de gordura saturada. A gordura saturada diminui os receptores de LDL, os quais estão envolvidos com a captação hepática de remanescentes (DAUMERIE et al., 1992; WOOLETT et al., 1992; SPADY et al., 1993; DIETSCHY DK, 1995; LAMBERT et al., 2000). Portanto, o menor consumo de gordura saturada pelos veganos e ovolacto-vegetarianos comparados com os onívoros pode ter contribuido com o clearance acelerado dos remanescentes observado nesse estudo. Além disso, analisando os três 
grupos, nossos dados mostram uma correlação negativa entre a quantidade de gordura saturada consumida e a remoção de remanescentes.

Weintraub et al. (1988) mostraram redução na lipemia pós-prandial com o consumo de gordura poliinsaturada, quando comparada com gordura saturada. A gordura poliinsaturada e a monoinsaturada também podem ativar o receptor de LDL (GRUNDY, 1987; VENTURA et al., 1989; GRUNDY e DENKE, 1990). Portanto, o aumento do consumo de gordura poliinsaturada observado no grupo vegano e o aumento do consumo de gordura monoinsaturada observado nos ovolacto-vegetarianos podem também estar relacionados ao aumento da remoção de remanescentes nesses dois grupos.

O fato dos vegetarianos consumirem menos colesterol que os onívoros (MESSINA e MESSINA, 1996; NAKAMOTO et al., 2008; CRAIG e MANGELS, 2009), dado também observado em nosso estudo, tanto com os veganos como com os ovolacto-vegetarianos, pode também ter influenciado o metabolismo dos remanescentes. Ginsberg et al. (1994) não observaram diferenças do alto consumo de colesterol por 8 semanas, na lipemia pósprandial, avaliada após dieta-teste e vitamina A. Usando o mesmo método baseado em emulsões artificiais, Maranhão et al. (CESAR et al., 2006) demonstraram que o alto consumo de colesterol, com a ingestão de três ovos por dia, diminuiu a remoção plasmática dos remanescentes. Em nosso estudo, o consumo de colesterol pelos ovolacto-vegetarianos e veganos (150 e 50 mg por dia, respectivamente) foi significativamente menor que pelos onívoros (250 mg por dia), o que pode ter contribuído com o aumento 
da remoção dos remanescentes. Além disso, observou-se também uma correlação negativa entre o consumo de colesterol e a remoção dos remanescentes. Nossos resultados sugerem que além de poder diminuir o LDL-C, como também demonstrado nesse estudo e em diversos outros (LICHTENSTEIN et al., 2006) o menor consumo de colesterol poderia proteger contra aterosclerose, acelerando a remoção dos remanescentes.

Por outro lado, em nosso estudo, veganos e ovolacto-vegetarianos consumiam maior quantidade de fibras, assim como em outros estudos (JANELLE e BARR, 1995; MESSINA e MESSINA, 1996; BARR e BROUGHTON, 2000 WALDMMAN et al., 2007; CRAIG, 2009), o que também pode estar envolvido com a remoção aumentada dos remanescentes encontrada, em nosso estudo, nesses dois grupos. $O$ consumo de fibras foi correlacionado com a taxa fracional de remoção do éster de colesterol da emulsão, indicando que quanto maior o consumo de fibras, maior a remoção dos remanescentes. Alguns estudos demonstraram uma redução na trigliceridemia pós-prandial (CARA et al., 1992; LIA et al., 1997) tanto com o alto consumo de fibras como com a adição de fibras em refeição-teste. Alguns estudos mostraram que a dieta vegetariana diminui a insulina e aumenta a sensibilidade à insulina (HUNG et al.,2006, BURKE et al., 2007) o que está, pelo menos em parte, relacionado ao maior consumo de fibras (ANDERSON et al.,1995), já que as fibras podem aumentar a captação dos remanescentes, estimulando o LRP (LAATSCH et al., 2009), receptor que também está envolvido com a captação hepática dos remanescentes (YU et al., 2001). 
No presente estudo, os indivíduos veganos consumiam uma maior quantidade de carboidratos que os ovolacto-vegetarianos e onívoros. Observou-se uma correlação positiva entre o consumo de carboidratos e a remoção dos remanescentes. Entretanto, dados da literatura mostram que o maior consumo de frutose, comum em vegetarianos, leva a um aumento da lipemia pós-prandial enquanto que o maior consumo de glicose pode aumentar ou não ter efeito (COHEN e BERGER, 1990; JEPPESEN et al., 1995).

Outro aspecto observado em nosso estudo, em relação à dieta dos veganos foi o menor consumo de proteínas quando comparados aos ovolacto-vegetarianos e onívoros. Quando analisados todos os grupos, observou-se uma correlação positiva entre o consumo de proteínas e a remoção dos remanescentes, ou seja, quanto menor o consumo de proteínas menor a remoção de remanescentes, o que vem de encontro com os resultados de Mamo et al. (2005) que mostraram que uma dieta pobre em proteína exacerba a lipemia pós-prandial. Portanto, no presente estudo, o menor consumo de proteína pelos veganos não deve ter influenciado no aumento da remoção plasmática dos remanescentes.

A remoção plasmática dos triglicérides da emulsão de quilomícrons foi similar em indivíduos veganos, ovolacto-vegetarianos e onívoros, indicando que o processo de lipólise dos triglicérides dos quilomícrons na parede vascular pela ação da lípase lipoprotéica encontra-se igualmente eficiente em vegetarianos e onívoros, o que foi confirmado pelo ensaio "in vitro" da medida da atividade dessa enzima. Weintraub et al. (1988) 
observaram que o consumo de gordura poiliinsaturada não mudou a atividade da lípase lipoprotéica in vitro, comparando-se com a gordura saturada. Entretanto, alguns estudos mostraram que a dieta poliinsaturada aumenta o processo de lipólise dos quilomícrons (SANDERS, 2003). Em nosso estudo, apesar do maior consumo de gordura poliinsaturada por parte dos veganos, não encontramos diferença comparando-se com onívoros. Isso pode ser explicado pelas diferentes metodologias utilizadas, visto que nos estudos de outros autores, a avaliação da lipólise foi realizada por meio dos próprios quilomícrons naturais dos participantes, enquanto que em nosso estudo, utilizou-se um quilomícrons artificial. Nesse sentido, Weintraub et al. (1988) demonstraram que os quilomícrons formados em indivíduos que consomem maior quantidade de gordura poliinsaturada possuem maior afinidade pela lipase lipoprotéica.

Em nosso estudo observou-se níveis mais baixos de LDL-C nos indivíduos veganos do que nos onívoros e nos ovolacto-vegetarianos. Esses dados estão de acordo com os referidos na literatura (TOOHEY ML et al.,1998, DE BIASE et al.,2007; CHEN et al., 2008; FRASER, 2009), indicando que uma dieta mais rígida, do ponto de vista do conteúdo de gorduras de origem animal proporciona um efeito maior no LDL-C. Quanto ao achado, em nosso trabalho, de níveis de LDL-C iguais em ovolactovegetarianos e onívoros, trata-se de ponto controverso, confirmado em alguns estudos (HARMAN et al., 1998), mas na maioria deles, houve realmente níveis mais baixos de LDL-C nos vegetarianos, comparados aos onívoros. É possível que isto se deva ao fato da maioria desses trabalhos 
(WEST, HAYES, 1968; FRASER, 2009) incluírem conjuntamente vegetarianos ovolacto-vegetarianos e veganos, diferentemente do nosso protocolo experimental, onde os dois grupos foram analisados separadamente. O consumo, pelos veganos, de uma proporção claramente muito menor de ácidos graxos saturados é o fator determinante do LDL-C menor neste grupo, pois o consumo de maior percentual de gordura saturada inibe a expressão dos receptores da LDL, fazendo com que haja acúmulo desta lipoproteína no plasma (GRUND e DENKE, 1990; MENSINK e KATAN, 1992; HEGSTED et al., 1993; MENSINK, 1993).

Em nosso estudo, não encontramos diferenças nos níveis de triglicérides entre os grupos estudados. Alguns estudos da literatura apresentaram o mesmo achado (LIN et al., 2001; CHELCHOWSKA et al.,2003), mas em outros trabalhos observou-se diminuição dos triglicérides nos vegetarianos (LU et al., 2000; DE BIASE et al., 2007). Essas variações reportadas na literatura provavelmente se devem a diferentes conteúdos das dietas em gordura poliinsaturada ou carboidratos (FAMODU et al., 1998).

Veganos, ovolacto-vegetarianos e onívoros não diferiram quanto aos níveis de HDL-C. Esses resultados confirmam os dados da literatura (CHELCHOWSKA et al., 2003; CHEN et al, 2008), embora, em outros estudos tenha havido diminuição do HDL-C nos vegetarianos (SACKS et al.,1975; RICHTER et al., 2004), provavelmente pela alta ingestão de alimentos ricos em gordura poliinsaturada e baixa ingestão de gordura saturada (MENSINK e KATAN, 1990; HEGSTED,1993; CLARKE, 1997). Também não foram encontradas diferenças em aspectos qualitativos da 
HDL avaliados no presente estudo, como o processo de transferência de lípides para a HDL e o tamanho dessa lipoproteína, entre os três grupos estudados. A transferência de lípides é um aspecto importante no metabolismo da HDL e nas principais funções dessa lipoproteína quais sejam na esterificação do colesterol plasmático e no transporte reverso do colesterol (GLOMSET, 1968; LO PRETE, 2009). Em relação ao tamanho da partícula da HDL, os resultados em trabalhos recentes são controversos (LE GOFF, 2004 e BARTER e RYE, 2006). De acordo com a literatura, o tamanho da HDL está relacionado principalmente ao conteúdo de éster de colesterol presente no interior da partícula (BARTER, 2006), o qual pode ser, em parte, determinado pelo processo de transferência de éster de colesterol. Em nosso estudo, não houve diferença no tamanho da HDL entre os grupos estudados, o que poderia ser explicado pelo fato de que a transferência de éster de colesterol da nanoemulsão para a HDL também não foi diferente.

Os dados do presente estudo mostram que a dieta vegetariana, tanto vegana como ovolacto-vegetariana, aumenta a remoção plasmática dos remanescentes de quilomícrons, lipoproteínas aterogênicas. Além disso, a dieta vegana também induz níveis mais baixos de LDL-C, importante fator de risco lipídico de aterosclerose. Tendo em vista estas considerações, as dietas vegana e ovolacto-vegetariana parecem ser mais favoráveis do ponto de vista de prevenção de aterosclerose comparada a onívoros. Esses resultados, provavelmente, estão relacionados com os efeitos benéficos da dieta vegetariana em relação às doenças cardiovasculares. 
CONCLUSÃO 


\section{CONCLUSÃO}

Podemos concluir, com os resultados do presente estudo, que os indivíduos que não consomem nenhum alimento de origem animal, os veganos e aqueles que incluem alimentos de origem animal em sua dieta, mas não ingerem carne, os ovolacto-vegetarianos, removem os remanescentes de quilomícrons mais rapidamente da circulação sanguínea, comparando-se com aqueles que incluem carne na dieta, os onívoros. Entretanto, o processo de lipólise dos quilomícrons não diferiu entre os três grupos estudados.

Além disso, a dieta vegana leva a níveis mais baixos do colesterol total, comparando-se com ovolacto-vegetarianos e onívoros. Em relação ao LDL-C, foi observado decréscimo no grupo dos veganos quando comparado com os onívoros. Não houve diferenças no VLDL-C, HDL-C e triglicérides entre os grupos estudados.

A transferência de lípides foi similar nos três grupos estudados, assim como o tamanho da HDL. 


\section{REFERÊNCIAS BIBLIOGRÁFICAS}

ACHA PN, SZYFRES B. Zoonosis y enfermedades transmisibles comunes al hombre y a los animales. 1989; $2^{\mathrm{a}}$ ed. Washington DC. OPS.

ACOSTA NAVARRO J, PRADO S, SANCHEZD et al. Blood pressure, blood lipids and other biochemical parameters among vegetarian, semivegetarian and omnivorus Peruvians. The Lima Study. JACC. 1998;31(5):Suppl C:373.

ALTMAN PL, DITTMER DS. Biology Data Book. In: ALTMAN PL; DITTMER DS, eds. Federation of the American Societies for Experimental Biology. 1974; Vol. III, Bethesda, Maryland, USA.

ANDERSON JW, O'NEAL DS, RIDDELL-MASON S, FLOORE TL, DILLON DW, OELTGEN PR. Postprandial serum glucose, insulin, and lipoprotein responses to high- and low-fiber diets. Metabolism. 1995;44(7):848-54.

APPLEBY PN, DAVEY GK, KEY TJ. Hypertension and blood pressure among meat eaters, fish eaters, vegetarians and vegans in EPIC-Oxford. Public Health Nutr. 2002;5:645-54.

APPLEBY PN, THOROGOOD M, MANN JI, KEY TJ. The Oxford Vegetarian Study: An overview. Am J Clin Nutr. 1999;70:S525-S31.

ARNTZENIUS AC, KROMHOUT D, BARTH JD, REIBER JH, BRUSCHKE $\mathrm{AV}, \mathrm{BUIS} \mathrm{B}$, et al. Diet, lipoproteins and the progression of coronary 
atherosclerosis. The Leiden Intervention Trial. $N$ Eng $J$ Med. 1985;312(3):805-11.

BACHORIK PS, RIFKIND BM, KWITEROVICH PO. Lipídeos e dislipoproteinemias. In: HENRY JB, Diagnósticos clínicos e tratamentos por métodos laboratoriais. 2ed. São Paulo, Manole, 1999.

BALL MJ, BARTLETT MA. Dietary intake and iron status of Australian vegetarian women. Am J Clin Nutr 1999;70:353.

BANSAL S, BURING JE, RIFAI N, MORA S, SACKS FM, RIDKER PM. Fasting compared with nonfasting triglycerides and risk of cardiovascular events in women. JAMA. 2007;18;298(3):309-16.

BARKER DJ, MORRIS J, NELSON M. Vegetable consumption and acute appendicitis in 59 areas in England and Wales. Br Med J. 1986;292:92730.

BARNARD ND, COHEN J, JENKINS DJA et al. A low-fat vegan diet improve glycemic control and cardiovascular risk factors in a randomized clinical trial Type 2 diabetes. Diabetes Care. 2006;29:1777-83.

BARNARD ND, SCIALLI AR, TURNER-MCGRIEVY G, LANOU AJ, GLASS $J$. The effects of a low-fat, plant-based dietary intervention on body weight, metabolism, and insulin sensitivity. Am J Med. 2005;118:991-7

BARR SI, BROUGHTON TM. Relative weight, weight loss efforts and nutrient intakes among health-conscious vegetarian, past vegetarian and nonvegetarian women ages 18 to 50. J Am Coll Nutr. 2000; 19(6):781-8.

BARSOTTI G. A special, supplemented "vegan" diet for neprhrotic patients. Am J Nephrol. 1991;11(5):380-5. 
BARTER PJ, RYE KA. Relationship between the concentration and antiatherogenic activity of high-density lipoproteins. Curr opin lipidol. 2006 aug;17(4):399-403.

BARTER PJ. HDL: A recipe for longevity. Atherosclerosis. 2004;5:25.

BATT KV, AVELLA M, MOORE EH, JACKSON B, SUCKLING KE, BOTHAM KM. Differential effects of low-density lipoprotein and chylomicron remnants on lipid accumulation in human macrophages. Exp Biol Med (Maywood). 2004;229(6):528-37.

BEAUMIER-GALLON G, DUBOIS C, SENFT M, VERGNES MF, PAULI AM, PORTUGAL H, LAIRON D. Dietary cholesterol is secreted in intestinally derived chylomicrons during several subsequent postprandial phases in healthy humans. Am J Clin Nutr. 2001 May;73(5):870-7.

BEISIEGEL U, WEBER W, OLIVECRONA GB. Lipoprotein lipase enhances the binding of chylomicron to low density lipoprotein receptor-related protein. Proc Natl Acad Sci. 1991;88:8342-6.

BERNARDES-SILVA H, TOFFOLETTO O, BORTOLOTTO LA, LATRILHA MC, KRIEGER EM, PILEGGI $F$, et al. Malignant hypertension is acompanied by marked alterations in chylomicron metabolism. Hypertension. 1995;26:1207-10.

BERSTEIN AM, TREYSON L, LI Z. Are high-protein, vegetable-based diets safe for Kidney function? A review of literature. J Am Diet Assoc. 2007;107:644-50.

BERR F, KERN F. Plasma clearance of chylomicrons labeled with retynil palmitate in health human subjects. $J$ Lipid Res. 1984;38:301-14. 
BISHOP JR, STANFORD KI, ESKO JD.Heparan sulfate proteoglycans and triglyceride-rich lipoprotein metabolism. Curr Opin Lipidol. 2008;19(3):30713.

BLANCHETTE-MACKIE EJ, SCOW RO. Effects of lipoprotein lipase on the structure of chylomicrons. J Cell Biol. 1973;6:689-708.

BORBA EF, BONFÁ E, VINAGRE CG, RAMIRES JA, MARANHÃO RC. Chylomicron metabolism is markedlyaltered in systemic lupus erythematosusArthritis Rheum. 2000;43(5):1033-40.

BOTHAM KM, BRAVO E, ELLIOTT J, WHEELER-JONES CP. Direct interaction of dietary lipids carried in chylomicron remnants with cells of the artery wall: implications for atherosclerosis development. Curr Pharm Des. 2005;11(28):3681-95.

BOXENBAUM H, RONFELD R. Interspecies pharmacokinetic scaling and the Dedrick plots. Am J Physiol. 1983;245(6):R768-75.

BRAITHWAITE $\mathrm{N}$, FRASER HS, MODESTE $\mathrm{N}$, BROOME $\mathrm{H}$, KING $\mathrm{R}$. Obesity, diabetes, hypertension, and vegetarian status among Seventhday Adventist in Barbados: Preliminary results. Eth Dis. 2003;81:380-87.

BROWN MS, GOLDSTEIN JL. A receptor-mediated pathway for cholesterol homeostasis. Science. 1986;232:34-47.

BROWN MS, KOVANEN PT, GOLDSTEIN JL. Regulation of plasma cholesterol by lipoprotein receptors. Science. 1981;212:628-35.

BURKE LE, HUDSON AG, WARZISKI MT, STYN MA, MUSIC E, ELCI OU, SEREIKA SM. Effects of a vegetarian diet and treatment preference on 
biochemical and dietary variables in overweight and obese adults: a randomized clinical trial. Am J Clin Nutr. 2007 Sep;86(3):588-96.

BURKITT D. Varicose veins, deep vein thrombosis and hemorrhoids: epidemiology and suggested a etiology. Br M J. 1972;2:556-61.

CARA L, DUBOIS C, BOREL P. Effects of oat bran, rice bran, wheat fiber and wheat germ on postprandial lipemia in health adults. Am J Clin Nutr., 1992;55:81-8.

CÉSAR tB, OliveIRA MR, MESQUitA CH, MARANHÃO RC. High cholesterol intake modifies chylomicron metabolism in normolipidemic young men. J Nutr. 2006;136(4):971-6.

CHACRA AP, SANTOS RD, AMÂNCIO RF, SCHREIBER R, RAMIRES JA, MARANHÃO RC. Clearence of a 3H-Labeled chylomicorn-like emulsion following the acute phase of myocardial infarction. Int $J$ Cardiol. 2004;93(2-3):181-7.

CHELCHOWSKA M, LASKOWSKA-KLITA T, KLEMARCZYK W. Lipids and vitamin A and E status in vegetarian children. Med Wieku Rozwoj. 2003;7(4 Pt 2): 577-85.

CHEN CW, LIN YL, LIN TK, LIN CT, CHEN BC, LIN CL. Total cardiovascular risk profile of Taiwanese vegetarian. Eur J Clin Nutr. 2008; 62:138-44.

CLARK R, FROST C, COLLINS R. APPLEBY P, PETO R. Dietary lipids and blood cholesterol: quantitative meta-analysis of metabolic ward studies. BMJ. 1997; 314:112-7. 
COHEN JC, BERGER GM. Effects of glucose ingestion on postprandial lipemia and triglyceride clearance in humans. J Lipid Res. 1990;31(4):597602.

COHN JS, JOHNSON EJ, MILLAR JS, COHN SD, MILNE RW, MARCEL YL, et al. Contribution of apo B 48 and apo B 100 triglycerides rich lipoproteins (TRL) to postprandial increases in the plasma concentration of $T R L$ triglycerides and retinyl esters. J Lipid Res. 1993;34:2033-40.

COOPER R, GOLDBERG R, TREVISAN M, TSONG Y, LIU K, STAMLER J, RUBENSTEIN A, et al. The selective lipid-lowering effect of vegetarianism on low density lipoproteins in a crossover experiment. Atherosclerosis. 1982;44 (3):293-306 .

CRAIG WJ. Health effects of vegan diets. Am $J$ Clin Nutr. 2009;89(suppl):S1627-33.

CRAIG WJ, MANGELS AR. American Dietetic Association. Position of the American Dietetic Association: vegetarian diets. J Am Diet Assoc. 2009;109(7):1266-82.

DAUMERIE CM, WOOLLETT LA, DIETSCHY JM. Fatty acids regulate hepatic low-density lipoprotein receptor activity through redistribution of intracellular cholesterol pools. Proc Natl Acad Sci USA. 1992;89:10797801.

DAVEY GK, SPENCE EA, APPLEBY PN, ALLEN NE, KNOX KH, KEY TJ. EPIC- Oxford: lifestyle characteristics and nutrient intakes in a cohort of 33,883 meat-eaters and 31,546 , non meat-eaters in the UK. Public Health Nutr. 2003;6:259-69. 
DE BIASE SG, FERNANDES SF, GIANINI RJ, DUARTE JL. Vegetarian diet and cholesterol and triglyceride levels. Arq Bras Cardiol. 2007;88:35-9.

DE MARCHI MA, MARANHÃO RC, BRANDIZZI LI, SOUZA DR. Effects of isotretinoin on the metabolism of triglyceride-rich lipoproteins and on the lipid profile in patients with acne. Arch Dermatol Res. 2006;297(9):403-8.

DIETSCHY DK. Experimental mechanism: regulation of plasma LDL cholesterol. Am J Clin Nutr. 1995;62: S679-S88.

DOI H, KUGIYAMA K, OKA H, SUGIYAMA S, OGATA N, KOIDE SI, et al. Remnant lipoproteins induce proatherothrombogenic molecules in endothelial cells through a redox-sensitive mechanism. Circulation. 2000;102(6):670-6.

DUBOIS C, ARMAND M, FEREZOU J, BEAUMIER G, PORTUGAL H, PAULI AM, et al. Postprandial appearance of dietary deuterated cholesterol in the chylomicron fraction and whole plasma in healthy subjects. Am J Clin Nutr. 1996;64:47-52.

DUBOIS C, ARMAND M, MEKKI N, PORTUGAL H, PAULI AM, BERNARD PM, LAFONT H, LAIRON D. Effects of increasing amounts of dietary cholesterol on postprandial lipemia and lipoproteins in human subjects. $J$ Lipid Res. 1994;35(11):1993-2007.

DUCHATEAU NP, PULLINGER RC, ORELLANA ER, KUNITAKE ST, NAYAVIGNE J, O'CONNOR PM, et al. Apoliprotein L, a New Human High Density Lipoprotein Apoliprotein Expressed by the Pancreas. J Biol Chem. 1997;10:255-76. 
ECKARDSTEIN AV, NOFER JR, ASSMANN G. High density lipoproteins and arteriosclerosis: Role od cholesterol efflux and reverse cholesterol transport. Arteriosclerosis Thromb Vasc Biol. 2001;21:13.

EISENBERG S. High density lipoprotein metabolism. J Lipid Res. $1984 ; 25: 1017-58$.

ELLIS FR, HOLESH DS, ELLIS JW. Incidence of osteoporosis in vegetarians and omnivores. Am J Clin Nutr. 1972;25:555-8.

ELLSWORTH JL, FONG LG, KRAEMER FB, COOPER AD. Differences in the processing of chylomicron remnants and beta-VLDL by macrophages. J Lipid Res. 1990;31(8):1399-411.

ELLSWORTH JL, KRAEMER FB, COOPER AD. Transport of beta-very low density lipoproteins and chylomicron remnants by macrophages is mediated by the low density lipoprotein receptor pathway. $J$ Biol Chem. 1987;262(5):2316-25.

ELSEGOOD CL, PAL S, ROACH PD, MAMO JC. Binding and uptake of chylomicron remnants by primary and THP-1 human monocyte-derived macrophages: determination of binding proteins. Clin Sci. 2001;101(2):111-9.

FAMODU AA, OSILESI O, MAKINDE YO, OSONUGA OA. Blood pressure and blood lipid levels among vegetarian, semi-vegetarian, and nonvegetarian native Africans. Clin Biochem. 1998;31:7:545-49.

FLOREN CH, CHAIT A.Uptake of chylomicron remnants by the native LDL receptor in human monocyte-derived macrophages. Biochim Biophys Acta. $1981 ; 24 ; 665(3): 608-11$. 
FOKKEMA MR, BROUWER DA, HASPERHOVEN MB, HETTEMA Y,BEMELMANS WJ, MUSKIET FA. Polyunsaturated fatty acid status of Dutch vegans and omnivores. Prostaglandins Leukot Essent Fatty Acids. 2000;63(5):279-85.

FRASER GE. Vegetarians diet: what do we know of their effects on common chronic diseases? Am J Clin Nutr. 2009;89(suppl):S1607-12.

FUJIOKA Y, COOPER AD, FONG LG. Multiple processes are involved in the uptake of chylomicron remnants by mouse peritoneal macrophages. $J$ Lipid Res. 1998 Dec;39(12):2339-49.

GEAR JS, WARE A, FIRSDOM P, MANN J, NOLAN DJ, BRODIBB AJ. Symptomless diverticular disease and intake of dietary fiber. Lancet. $1977 ;(8115): 511-4$.

GIANNINI SD, DIAMENT J, SILVA PDE P. Lipoprotein lipase activity following heparin infusion. II. Patients with healed myocardial infarct. Rev Hosp Clin Fac Med Sao Paulo. 1970;25(2):91-8.

GINSBERG HN, KARMALLY W, SIDDIQUI M, HOLLERAN S, TALL AR, RUMSEY SC, et al. A dose-response study of the effects of dietary cholesterol on fasting and postprandial lipid and lipoprotein metabolism in healthy young men. Arterioscler Thromb. 1994 Apr;14(4):576-86.

GINSBURG GS, SMALL DM, ATKINSON D. Microemulsion of phospholipids and cholesterol esthers.Protein-free models of low-density lipoprotein. $J$ Biol Chem. 1982;257:8216-27.

GLOMSET JA. The plasma lecithins:cholesterol acyltransferase reaction. J Lipid Res. 1968a;9(2):155-67 
GLOMSET JA. Physiological role of lecithin-cholesterol acyltransferase. Am Clin Nutr. 1970b;23:1129-36.

GOLDSTEIN JL, ANDERSON RGW, BROWN MS. Coated pits, coated vesicles, and receptor-mediated endocytosis. Nature. 1979;279:679-85.

GOTTO AM. High density lipoproteins: biochemical and metabolic factors. Am J Cardiol. 1983;52:2-4.

GROOT PHE, VAN STIPHOUT WAHJ, KRAUSS XH, JANSEN H, VAN TOL A, VAN RAMSHORST E, et al. Postprandial lipoprotein metabolism in normolipidemic men with or without coronary artery disease. Arterioscler Thromb. 1991;11:653-62.

GRUNDY SM. Monounsaturated fatty acids, plasma cholesterol, and coronary heart disease. Am J Clin Nutr. 1987;45:1168-75.

GRUNDY SM, DENKE MA. Dietary influences on serum lipids and lipoproteins. J Lipids Res. 1990;31:1149-72

HARMAN SK, PARNELL WR. The nutritional health of New Zealand vegetarian and non-vegetarian Seventh-day Adventists: selected vitamin, mineral and lipid levels. NZ Med J. 1998 Mar 27;111(1062):91-4.

HEBBELINCK M, CLARYS P. Physical growth and development of vegetarian children and adolescents. In: Sabate J, ed. Vegetarian Nutrition. Boca Raton, FL:CRC Press. 2001;73-193.

HEGSTED DM, AUSMAN LM, JOHNSON JA, DALLAL GE. Dietary fat and serum lipids: an evaluation of the experimental data. Am J Clin Nutr. 1993 Jun;57(6):875-83. Review. Erratum in: Am J Clin Nutr. 1993Aug;58(2):245. 
HIRATA MH, OLIVEIRA HCF, QUINTÃO ECR, REDGRAVE TG, MARANHÃO RC. The effects of Triton WR-1339, protamine sulfate and heparin on the plasma removal of emulsion models of chylomicron and remnants in rats. Biochim Biophys Acta. 1987;917:314-44.

HOSNI JJ, VINAGRE CG, MADY C, MARANHÃO RC. Lipolysis of emulsion models of triglyceride-rich lipoproteins is altered in male patients with abdominal aorta aneurysm. Braz J Med Biol Res. 2007;40(3):305-7.

HU FB. Plant-Based foods and prevention of cardiovascular disease: an overview. Am J Clin Nutr. 2003;78(Suppl):S544-S51.

HU FB, RIMM EB, STAMPFER MJ, ASCHERIO A, SPIEGELMAN D, WILLETT. WC. Prospective study of major dietary patterns and risk of coronary heart disease in men. .Am J Clin Nutr. 2000 Oct;72(4):912-21.

HUNG CJ, HUANG PC, LI YH, LU SC, HO LT, CHOU HF. Taimanese vegetarians have higher insulin sensitivity than omnivores. $\mathrm{Br} J$ Nutr. 2006;95(1):129-35.

HUSSAIN MM, FATMA S, PAN X, Iqbal J. Intestinal lipoprotein assembly. Curr Opin Lipidol. 2005;16:281-5.

HUSSAIN MM, KANCHA RK, ZHOU Z, LUCHOOMUN J, ZU H, BAKILLAH A. Chylomicron assembly and catabolism: role of apolipoproteins and receptors. Biochim Biophys Acta. 1996;1300:151-70.

JACKSON KG, WOLSTENCROFT EJ, BATEMAN PA, YAQOOB P, WILLIAMS CM. Greater enrichment of triacylglycerol-rich lipoproteins with apolipoproteins $\mathrm{E}$ and $\mathrm{C}$-III after meals rich in saturated fatty acids than 
after meals rich in unsaturated fatty acids. Am J Clin Nutr. 2005;81(1):2534.

JACOB RA, BURRI BJ. Oxidative damage and defense. Am J Clin Nutr. 1996;63: S985-S90.

JANELLE KC, BARR SL. Nutrient intakes and eating behavior scores of vegetarian and non-vegetarian women. J Am Diet Assoc. 1995;95:180-9.

JEPPESEN J, CHEN YD, ZHOU MY, WANG T, REAVEN GM. Effect of variations in oral fat and carbohydrate load on postprandial lipemia. $A m J$ Clin Nutr. 1995;62(6):1201-5.

JOHNSTON PK. Implicações nutricionais das dietas vegetarianas. In: Shils ME, editor, Olson JÁ, Shike M, Ross AC. Tratado de nutrição moderna na saúde e na doença. $9^{\circ}$ ed. Barueri, SP: Manole. 2003;1885-98.

KARPE F, STEINER G, UFFELMAN K, OLIVECRONA T, HAMSTEN A. Postprandial lipoproteins and progression of coronary atherosclerosis. Atherosclerosis. 1994;106:83-97.

KAWAKAMI A, TANAKA A, NAKANO T, SANIABADI A, NUMANO $F$. Stimulation of arterial smooth muscle cell proliferation by remnant lipoprotein particles isolated by immuno-affinity chromatography with antiapo A-I and anti-apo B-100. Horm Metab Res. 2001;33(2):67-72.

KAWASAKI S, TANIGUCHI T, FUJIOKA Y, TAKAHASHI A, TAKAHASHI T, DOMOTO K, et al. Chylomicron remnant induces apoptosis in vascular endothelial cells. Ann N Y Acad Sci. 2000;902:336-41. 
KEY TJ, APPLEBY PN, SPENCER EA, TRAVIS RC, ALLEN NE, THOROGOOD $\mathrm{M}$, et al. Cancer incidence in British vegetarians. $\mathrm{Br} J$ Cancer. 2009;101(1):192-7.

KEY TJ, FRASER GE, THOROGOOD M, APPLEBY PN, BERAL V, REEVES G, BURR ML, et al. Mortality in vegetarians and non-vegetarians: Detailed findings from a collaborative analyses of 5 prospective studies. Am J Clin Nutr. 1999;70:S516-S24.

KNUTSEN MD, HOGGANVIK A. Cholesterol lowering effect of a 12-day vegan diet. Am J Clin Nutr. 1988;48(3):920.

KOLOVOU GD, ANAGNOSTOPOULOU KK, DASKALOPOULOU SS, MIKHAILIDIS D, COKKINOS D. Clinical relevance of postprandial lipaemia. Curr Med Chem. 2005;12:1931-45.

KOO C, WERNETTE-HAMMOND ME, GARCIA Z, MALLOY MJ, UAUY R, EAST C, et al. Uptake of cholesterol-rich remnant lipoproteins by human monocyte-derived macrophages is mediated by low density lipoprotein receptors. J Clin Invest. 1988;81(5):1332-40.

KORNSTEINER M, SINGER I, ELMADFA I. Very Low n-3 Long-Chain Polyunsaturated Fatty Acid Status in Austrian Vegetarians and Vegans. Ann Nutr Metab 2008;52:37-47

KORPELA R, SEPPO L, LAAKSO J, LILJA J, KARJALA K, LÄHTEENMÄKI $\mathrm{T}$, et al. Dietary habits affect the susceptibility of low-density lipoprotein to oxidation. Eur J Clin Nutr. 1999;53(10):802-7.

KUGIYAMA K, DOI H, MOTOYAMA T, SOEJIMA H, SOEJIMA H, MISUMI K, KAWANO $\mathrm{H}$, et al. Association of remnant lipoprotein levels with 
impairment of endothelium-dependent vasomotor function in human coronary arteries. Circulation. 1998;97(25):2519-26.

KWITEROVICH JR., PO. The metabolic pathways of high-density lipoprotein, low-density lipoprotein, and triglycerides: a current review. Am J Cardiol. 2000;86:452.

LAATSCH A, MERKEL M, TALMUD PJ, GREWAL T, BEISIEGEL U, HEEREN J. Insulin stimulates hepatic low density lipoprotein receptorrelated protein 1 (LRP1) to increase postprandial lipoprotein clearance. Atherosclerosis. 2009;204(1):105-11.

LAMBERT MS, AVELA MA, BERHANE Y, SHERVILL E, BOTHAM KM. The fatty acid composition chylomicron remnants influences their binding and internalization by isolated hepatocites. Eur J Biochem. 2001;268:3983-92.

LAMBERT MS, AVELA MA, BOTHAM KM, MAYES PA. The type of dietary fat alters the hepatic uptake and biliary excretion of cholesterol from chylomicron remnants. Brithish J Nutr. 2000;83:431-38.

LAMBERT MS, BOTHAM KM, MAYES PA. Variations in composition of dietary fats affect hepatic uptake and metabolism of chylomicron remnant. Biochem J. 1995;310:845-52.

LE GOFF W, GUERIN M, CHAPMAN MJ. Pharmacological modulation of cholesteryl ester transfer protein, a new therapeutic target in atherogenic dyslipidemia. Pharmacol Ther. 2004;101(1):17-38.

LEKHAL S, BORVIK T, NORDOY A, HANSEN JB. Increased postprandial otriglyceride-rich lipoprotein levels in elderly survivors of myocardial infarction. Lipids. 2008;43(6):507-15. 
LEWIS GF, RADER DJ. New insights into the regulations of HDL metabolism and reverse cholesterol transport. Circ Res. 2006;96:122.

LIA A, ANDERSSON H, MEKKI N, JUHEL C, SENFT M, LAIRON D. Postprandial lipemia in relation to sterol and fat excretion in ileostomy subjects given oat bran and wheat test meals. Am J Clin Nutr. 1997;66:357-65.

LI D, SINCLAIR A, MANN N, BALL M, KELLY F, ABEDIN L, et al. The association of diet and thrombotic risk factors in healthy male vegetarians and meat-eaters. Eur J Nutr. 1999;53(8):612-9 .

LICHTENSTEIN AH, APPEL LJ, BRANDS $M$ et al. AMERICAN HEART ASSOCIATION NUTRITION COMMITTEE. Diet and lifestyle recommendations revision 2006: a scientific statement from the American Heart Association Nutrition Committee. Circulation 2006;114:82-96

LIMA E, MARANHÃO RC. Rapid, simple laser-light scattering method for HDL particle size in whole plasma. Clinical Chemistry. 2004;50:1086.

LIN CL, FANG TC, GUENG MK. Vascular dilatory functions of ovolactovegetarians compared with omnivores. Atherosclerosis. 2001;158(1):247-51.

LING WA. Shifting from conventional diet to a uncooked "vegan" diet reversibly alters serum lipid and apolipoprotein levels. Nutr Res. 1992;12(12):1431-40.

LITHELL HA. Changes in lipoprotein metabolism during a supplemented fast and an ensuing vegetarian diet period. Upsala J Med Sci. 1985;90(1):7384. 
LIU S, LEE IM, AJANI U, COLE SR, BURING JE, MANSON JE Intake of vegetables rich in carotenoids and risk of coronary heart disease in men: The Physicians' Health Study. Int J Epidemiol. 2001;30(1):130-5.

LO PRETE AC, DINA CH, AZEVEDO CH, PUK CG, LOPES NH, HUEB WA, et al. In vitro simultaneous Transfer of Lipids to HDL in Coronary Artery Disease and in Statin Treatment. Lipids. 2009; 44(10):917-24.

LU SC, WU WH, LEE CA, CHOU HF, LEE HR, HUANG PC. LDL of Taiwanese vegetarian are less oxidizable than those of omnivores. J Nutr. 2000;130(6):1591-6.

MAHON AK, FLYNN MG, STEWART LK, MCFARLIN BK, IGLAY HB, MATTES RD, et al. Protein intake during energy restriction: Effects on body composition and markers of metabolic and cardiovascular health in postmenopausal women. J Am Coll Nutr. 2007;26:182-89.

MALHOTRA KK. Clinical and biochemical evaluation of low protein diet in chronic renal failure in Indian. Indian J Med Res. 1993;119(1):79-85.

MAMO JC, JAMES AP, SOARES MJ, GRIFFITHS DG, PURCELL K, SCHWENKE JL. A low-protein diet exacerbates postprandial chylomicron concentration in moderately Dyslipidaemic subjects in comparison to a lean red meat protein-enriched diet. Eur J Clin Nutr. 2005;59(10):1142-8.

MAMO JCL, WHEELER JR. Chylomicrons or their remnants penetrate rabbit thoracic aorta as efficiently as do smaller macromolecules, including lowdensity lipoprotein, high-density lipoprotein, and albumin. Coron Art Dis. 1994;5:695-705. 
MANGELS AR, MESSINA V. Considarations in planning vegans diet: infants. J Am Diet Associ. 2001;10:670-77.

MARANHÃO RC, CESAR TB, PEDROSO-MARIANI S, HIRATA MH, MESQUITA CH. Metabolic behavior in rats of a non-protein microemulsion resembling low-density lipoprotein. Lipids. 1993;28:691-6.

MARANHÃO RC, LINCOLN EC, BRUNEGRABER H, SMALL DM, REDGRAVE TG. The clearance of lipid recombinant lipoprotein models resembling chylomicrons and their remnants. Circulation. 1984;70:299315.

MARANHÃO RC, FERES MC, MARTINS MT, MESQUITA CH, TOFFOLETTO O, VINAGRE CG, et al. Plasma kinetics of a chylomicronlike emulsion in patients with coronary artery disease. Atherosclerosis. $1996 ; 126: 15-25$.

MARANHÃO RC, QUINTÃO EC. Long term steroid metabolism balance studies in subjects on cholesterol-free and cholesterol-rich diets: comparison between normal and hypercholesterolemic individuals. J Lipid Res. 1983;24(2):167-73.

MARCEL YL, VEZINA C, TENG B, SNIDERMAN A. Transfer of cholesterol esters between human high density lipoprotein and triglyceride-rich lipoproteins controlled by a plasma protein factor. Atherosclerosis. $1980 ; 35: 127$.

MEKKI N, CHARBONNIER M, BOREL P, LEONARDI J, JUHEL C, PORTUGAL H, LAIRON D. Butter differs from olive oil and sunflower oil in 
its effects on postprandial lipemia and triacylglycerol-rich lipoproteins after single mixed meals in healthy young men. J Nutr. 2002;132(12):3642-9.

MELBY CL, TOOHEY ML, CEBRIK J. Blood pressure and blood lipids among vegetarian, semi-vegetarian and non-vegetarian African Americans. Am J Clin Nutr. 1994;59:103-9.

MELINA V, DAVIS B, HARRISON V. A dieta saudável dos vegetais: o guia completo para uma nova alimentação. Rio de Janeiro: Campus; 1998

MENSINK RP, KATAN MB. Effect of dietary trans fatty acids on high-density and low-density lipoprotein cholesterol levels in healthy subjects. $N$ Engl $J$ Med. 1990 Aug 16;323(7):439-45.

MENSINK RP, KATAN MB. Effect of dietary fatty acids on serum lipids and lipoproteins. A meta-analysis of 27 trials. Arterioscler Thromb. 1992;12(8):911-9.

MENSINK RP. Effects of the individual saturated fatty acids on serum lipids and lipoproteins concentration. Am J Clin Nutr. 1993;57:S711-S14.

MESQUITA CH. Cinética do quilomícron marcado com ${ }^{3} \mathrm{H}-\mathrm{TG}$ e ${ }^{14} \mathrm{C}-\mathrm{CE}$. Análise compartimental auxiliar. São Paulo: Instituto de Pesquisas Energéticas e Nucleares (IPEN), 1994. [Publicações IPEN]

MESSINA MJ, MESSINA VL. The dietitian's Guide to Vegetarians Diets: Issue and Applications. Gaithersburg, MD: Aspen Publishers; 1996.

MESSINA V, MANGELS AR. Considerations in planning vegan diets: Children. J Am Diet Assoc. 2001;101:661-69.

MEYER E, WESTERVELD T, RUYTER-MEIJSTEK FC, VAN GREEVENBROEK MM, RIENKS R, VAN RIJN HJ, et al. Abnormal 
postprandial apolipoprotein B-48 and triglyceride responses in normolipidemic women with greater than $70 \%$ stenotic coronary artery disease: a case-control study. Atherosclerosis Shannon. 1996;124:221235.

NAKAMOTO K, WATANABE $\mathrm{S}$, KUDO $\mathrm{H}$, TANAKA A. Nutritional characteristics of middle-aged Japanese vegetarians. $J$ Atheroscler Thromb. 2008;15(3):122-9.

NAPOLITANO M, RIVABENE R, AVELLA M, BOTHAM KM, BRAVO E. The internal redox balance of the cells influences the metabolism of lipids of dietary origin by $\mathbf{J 7 7 4}$ macrophages: implications for foam cell formation. $J$ Vasc Res. 2001;38(4):350-60.

National Cholesterol Education Program - Adult Treatment Panel III Report 2001;www.nhli.nih.gov

NERVI FO, WEIS HJ, DIETSCHY JM. The kinetic characteristics of inhibition of hepatic cholesterogenesis by lipoproteins of intestinal origin. $\mathrm{J} B \mathrm{Biol}$ Chem. 1975;250:4145-51.

NORDESTGAARD BG, KONTULA K, BENN M, DAHLÖF B, DE FAIRE U, EDELMAN JM, et al. Effect of ACE insertion/deletion and 12 other polymorphisms on clinical outcomes and response to treatment in the LIFE study. Pharmacogenet Genomics. 2010 Feb;20(2):77-85.

OTAROD JK, GOLDBERG IJ. Lipoprotein lipase and its role in regulation of plasma lipoproteins and cardiac risk. Curr Atheroscler Rep. 2004;6:33542. 
PAL S, SEMORINE K, WATTS GF, MAMO J. Identification of lipoproteins of intestinal origin in human atherosclerotic plaque. Clin Chem Lab Med. $2003 ; 41(6): 792-5$

PATSCH J. Influence of lipolysis on chylomicron clearance and HDL cholesterol levels. Eur Heart J. 1998;19Suppl H:H2-H6.

PATSCH JR, MIESENBOCK G, HOPFERWIESER T, MÜHLBERGER V, KNAPP E, DUNN JK, et al. Relation of triglyceride metabolism and coronary artery disease. Studies in the postprandial state. Arterioscler Thromb. 1992;12(11):1336-45.

PROCTOR S, MAMO JCL. Arterial fatty lesions have increased uptake of chylomicron remnants but not low-density lipoproteins. Coron Arter Dis. $1996 ; 7: 239-45$.

PROCTOR SD, VINE DF, MAMO JC. Arterial permeability and efflux of apolipoprotein B-containing lipoproteins assessed by in situ perfusion and three-dimensional quantitative confocal microscopy. Arterioscler Thromb Vasc Biol. 2004;24(11):2162-7.

PUK CG, BOCCHI EA, LO PRETE AC, FERREIRA SM, STOLF NA, MARANHÃO RC. Transfer of cholesterol and other lipids from a lipid nanoemulsion to high-density lipoprotein in heart transplant patients. $J$ Heart Lung Transplant. 2009;28(10):1075-80.

QUINN D, SHIRAI K, JACKSON RL. Lipoprotein lipase: mechanism of action and role in lipoprotein metabolism. Prog Lipid Res. 1982;22:35-78. 
RASSIN T, LIRON M, RUBINSTEIN A, ARAD J, WEINTRAUB M. Vitamin A loading an indicator of post-prandial lipoprotein clearance in healthy and hypertrygliceridemic subjects. Isr J Med Sci. 1992;28:706-10.

REDGRAVE TG. Formation and metabolism of chylomicrons. Int Rev Physiol. 1983;28:103-30.

RESNICOW K, BARONE J, ENGLE A, MILLER S, HALEY NJ, FLEMING D, et al. Diet and serum lipids in vegan vegetarians: a model for risk reduction. J Am Diet Assoc. 1991;91:447-53.

RICHTER V, RASSOUL $F$, HENTSCHEL B, KOTHE K, KROBARA M, UNGER R, et al. Age-dependence of lipid parameters in the general population and vegetarians. $Z$ Gerontol geriatr. 2004;37(3):207-13.

ROBERTSON WG, PEACOCK M, HEYBURN PJ, HANES FA, RUTHERFORD A, CLEMENTSON E, et al. Should recurrent calcium oxalate stone formers become vegetarians? Br J Urol. 1979;51(6):427-31.

ROCHE HM, ZAMPELAS A, JACKSON KG, WILLIAMS CM, GIBNEY MJ. The effect of test meal monounsaturated fatty acid: saturated fatty acid ratio on postprandial lipid metabolism. Br J Nutr. 1998b;79(5):419-24.

ROCHE HM, ZAMPELAS A, KNAPPER JM, WEBB D, BROOKS C, JACKSON KG, et al. Effect of long-term olive oil dietary intervention on postprandial triacylglycerol and factor VII metabolism. Am J Clin Nutr. 1998a;68(3):552-60.

ROSELL MS, LLOYD-WRIGHT Z, APPLEBY PN, SANDERS TA, ALLEN NE, KEY TJ. Long-chain n-3 polyunsaturated fatty acids in plasma in British 
meat-eating, vegetarian, and vegan men. Am J Clin Nutr. 2005;82(2):32734.

ROSNER, B. Fundamentals of Biostatistics - Boston, PWS Publishers, Second edition 1986; 584.

SACKS FM, CASTELLI WP, DONNER A, KASS EH. Plasma lipids and lipoproteins in vegetarians and controls. N Eng J Med. 1975;292(22):114852.

SABATÉ J. The contribution of vegetarian diets to health and disease: a paradigm shift? Am J Clin Nutr. 2003;78Suppl 3:S502-7.

SANDERS TA. Dietary fat and postprandial lipids. Curr Atheroscler Rep. $2003 ; 5(6): 445-51$.

SANIABADI AR, UMEMURA K, SHIMOYAMA M, ADACHI M, NAKANO M, NAKASHIMA M. Aggregation of human blood platelets by remnant like lipoprotein particles of plasma chylomicrons and very low density lipoproteins. Thromb Haemost. 1997;77(5):996-1001.

SCHNEEMAN BO, KOTITE L, TODD KM, HAVEL RJ. Relationship between the responses of triglyceride-rich lipoproteins in blood plasma containing apolipoproteins B 48 and B 100 to a fat-containing meal in normolipidemic humans. Proc Natl Acad Sci. 1993;90:2069-73.

SMITH EM. Dose estimate tecniques. In: Nuclear medicine physics, instrumentation and agents. - Mosby, 1977.

SNOWDON DA, PHILLIPS R. Does a vegetarian diet reduce the occurrence of diabetes? Am J Public Health. 1985;75(5):507-12. 
SOWBY FS. Radiation Protection. ICRP publication 30. Part I. LIMITS FOR INTAKES OF RADIONUCLIDES BY WORKERS. In: SWOBY, FS. Ed Pergamon, Oxford, England, 1984

SPADY DK, WOOLLETT LA, DIETSCHY JM. Regulation of plasma LDLcholesterol levels by dietary cholesterol and fatty acids. Annu Rev Nutr. 1993;33:355-81.

SPOSITO AC, VENTURA LI, VINAGRE CG, LEMOS PA, QUINTELLA E, SANTOS RD, et al. Delayed intravascular catabolism of chylomicron like emulsion an independent predictor of coronary artery disease. Atherosclerosis. 2004b;176(2):397-403.

SPOSITO AC, LEMOS PA, SANTOS RD, HUEB W, VINAGRE CG, QUINTELLA Eet al. Impaired intravascular triglyceride lipolysis constitutes a marker of clinical outcome in patients with stable angina undergoing secondary prevention treatment: a long-term follow-up study. J Am Coll Cardiol. 2004a;43(12):2225-32.

SPOSITO AC, SANTOS RD, HUEB W, VENTURA LI, VINAGRE CC, RAMIRES JA et al. LDL concentration is correlated with the removal from the plasma of a chylomicron-like emulsion in subjects with coronary artery disease. Atherosclerosis. 2002;161(2):447-53.

STAHLER C. How many adults are vegetarian? The Vegetarian Research Group Web site http://www.vrg.org/journal/vj2006issue4/vj2006issue4poll.htm.Poster December 20, 2006. Acessed January20, 2009. 
STAHLER C. How many youth are vegetarian? The Vegetarian Research Group

Website.http://www.vrg.org/journal/vj2005issue4/vj2005issue4youth.htm. Poster October 7, 2005. Acessed January20, 2009.

STAMPFER MJ, HU FB, MANSON JE, RIMM EB, WILLETT WC. Primary prevention of coronary heart disease in women through diet and lifestyle. N Engl J Med. 2000;343(1):16-22.

SULTAN F, CARDONA-SANCLEMENTE LE, LAGRANGE D, LUTTON C, GRIGLIO S. Lipoprotein lipase and hepatic lipase activities in a hypercholesterolaemic (RICO) strain of rat. Effect of dietary cholesterol. Biochem J. 1990 Mar 1;266(2):349-53.

TEIXEIRA RCMA, MOLINA MCB, ZANDONADE E, MILL JG. Cardiovascular Risk in Vegetarian and Omnivores: A Comparative Study. Arq Bras Cardiol. 2007;89(4):214-221.

The Six Report of the Joint National Committee on the prevention, detection, evaluation and treatment of high blood pressure. Arch Intern Med. 1997;157:2413-46.

TONSTAD S, BUTLER T, YAN R, FRASER GE. Type of vegetarian diet, body weight, and prevalence of type 2 diabetes. Diabetes Care. 2009; 32(5):791-6.

TOOHEY ML, HARRIS MA, DEWITT W, FOSTER G, SCHMIDT WD, MELBY CL. Cardiovascular disease risk factors are lower in AfricanAmerican vegans compared to lacto-ovo-vegetarians. J Am Coll Nutr. 1998;17(5):425-34 . 
VAN LENTEN BJ, FOGELMAN AM, JACKSON RL, SHAPIRO S, HABERLAND ME, EDWARDS PA. Receptor-mediated uptake of remnant lipoproteins by cholesterol-loaded human monocyte-macrophages. J Biol Chem. 1985;260(15):8783-8.

VANG A, SINGH PN, LEE JW, HADDAD EH. Meat, processed meats, obesity, weight gain and occurrence of diabetes among adults: findings from the Adventist Health Studies. Ann Nutr Metab. 2008;52:96-104.

Vegetarian Nutrition and Cardiovascular Disease. American Dietetic Association Evidence Analysis Library Web site. http://www.adaevidencelibrary.com/topic.cfm?cat=3536. Accessed March 17, 2009.

VENTURA MA, WOOLLETT LA, SPADY DK. Dietary fish oil stimulates hepatic low density lipoprotein transport in the rat. $J$ Clin Invest. 1989;84(2):528-37.

VINAGRE CG, STOLF NA, BOCCHI E, MARANHÃO RC. Chylomicrons metabolism in patients submitted to cardiac transplantation. Transplantation. 2000; 27;69(4):532-7.

WALDMMAN A, KOSCHIZKE JW, LEITZMANN C, HOHN A. German vegan study: diet, life-style factors, and cardiovascular risk profile. Ann Nutr Metab. 2005;49(6):366-72.

WALDMANN A, STRÖHLE A, KOSCHIZKE JW, LEITZMANN C, HAHN A. Overall glycemic index and glycemic load of vegan diets in relation to plasma lipoproteins and triacylglycerols. Ann Nutr Metab. 2007;51(4):33544. 
WANG H, ECKEL RH. Lipoprotein lipase: from gene to obesity. Am J Physiol Endocrinol Metabolism. 2009;297:E271-88.

WEINTRAUB MS, GROSSKOPF I, RASSIN T, et al. Clearance of chylomicron remnants in normolipidemic patients with coronary artery disease: case control study over three years. Br Med J. 1996;935-9.

WEINTRAUB MS, ZECHNER R, BROWN A, EISENBERG S, BRESLOW JL. Dietary polyunsaturated fats of the W-6 and W-3 series reduce postprandial lipoprotein levels. Chronic and acute effects of fat saturation on postprandial lipoprotein metabolism. J Clin Invest. 1988;82(6):1884-93.

WEST F, HAYE S. Diet and serum cholesterol levels. A comparison between vegetarians and non-vegetarians in Seventh-Day Adventist group. Am J Clin Nutr. 1968;21:853-62.

WINDLER EET, GREEVE J, DAERR WH, GRETEN $\mathrm{H}$. Binding of rat chylomicrons and their remnants to the hepatic low-density-lipoprotein receptor and its role in remnant removal. Biochem J. 1988;252:553-61.

WOOLLETT LA, SPADY DK, DIETSCHY JM. Saturated and unsaturated fatty acids independently regulate low density lipoprotein receptor activity and production rate. J Lipid Res. 1992;33(1):77-88.

YANCEY PG, BORTNICK AE, KELLNER-WEIBEL G, de la LLERA-MOYA M, PHILLIPS MC, ROTHBLAT GH.Importance of different pathways os cellular cholesterol efflux. Arterioscler Thromb $\square$ Vasc Biol. 2003;23:712.

YU KC, MAMO JC. Chylomicron-remnant-induced foam cell formation and cytotoxici4y: a possible mechanism of cell death in atherosclerosis. Clin Sci (Lond). 2000; 98(2):183-92. 
YU KC, COOPER AD. Postprandial lipoproteins and atherosclerosis. Front Biosci. 2001;6:D332-54.

ZAMPELAS A, PEEL AS, GOULD BJ, WRIGHT J, WILLIAMS CM. Polyunsaturated fatty acids of the $n-6$ and $n-3$ series: effects on postprandial lipid and apolipoprotein levels in healthy men. Eur J Clin Nutr. 1994;48(12):842-8.

ZILVERSMIT DB. Atherogenesis: a postprandial phenomenon. Circulation. 1979;60(3):473-85 . 


\section{ANEXO 1 \\ QUESTIONÁRIO}

\section{DADOS GERAIS}

1. Nome Completo:

2. Sexo: $M \quad F \quad$ 3. Idade: $\quad$ 4. Data de nascimento:

5. Ocupação:

6. Grau de instrução: $\quad 1^{2}$ Grau

$2^{\circ} \mathrm{Grau} \quad 3^{\circ} \mathrm{Grau}$

7. Endereço:

8. CEP:

9. Fone residencial:

10.Celular:

11. e-mail:

\section{ESTILO DE VIDA}

12. Você é:

a) Ovolacto-vegetariano (não consome nenhum tipo de carne por pelo menos 5 anos)

b) Vegano (não consome nenhum tipo de alimento de origem animal) por pelo menos 5 anos)

c) Onívoro (consome qualquer tipo de alimento de origem vegetal ou animal)

13. Há quanto tempo você é lacto-ovo-vegetariano ou semi-vegetariano?

a) De 5-10 anos

b) De 10-15 anos

c) Mais de 15 anos

d) de nascença

14. Recebeu alguma orientação alimentar durante sua modificação?

a) Sim, nutricionista

b) Sim, médico

c) Sim, de outroprofisssional

d) Não

15. Se você for semi-vegetariano ou onívoro, você consome:

a) Carne Vermelha

b) Frango

c) Peixe

d) Frango e Peixe

e) Todas 
16. Faz ou já fez uso de suplementos nutricionais?
a) Nunca
b) 3-4 vezes/ semana
c) 5-7 ou mais vezes
d) 2 vezes ao dia

17. Atividade física

a) Nenhuma (sedentário)

b) Atividade moderada ( 2 a 3 vezes/semana)

c) Exercício ativo (4 a 5 vezes/semana )

d) Exercício intenso (esporte competitivo treinamento forte várias vezes/semana)

18.Consumo de tabaco
a) Nunca fumou
b) Fumante antigo (não fuma mais)
c) Fumante (1-9 cigarros/dia)
d) Fumante pesado (>10 cigarros/dia)

19. Consumo de bebidas alcóolicas
a) Nunca bebeu
b) 2 vezes/mês
c) $1 \mathrm{vez} / \mathrm{mês}$
d) 2 ou mais vezes/semana

20. Você tem algum familiar de primeiro grau (pais, irmãos) que sofre ou sofreu de cardiopatia precoce (para homem $<55$ anos e mulher $<65$ anos)?
a) Sim
b) Não

21. Você sofre de alguma doença crônica? Assinale Sim ou Não

- Cardiopatia (doença do coração) sim não

- Hipertensão arterial (pressão alta) sim não

- Diabete melito sim não

- Dislipidemia (colesterol alto) sim não

- Gota sim não

- Hepatopatia (insuficiência hepática crônica) sim não

- Nefropatia (insuficiência renal crônica) sim não

- Outra Se for SIM, indique qual:

sim não

22. Faz uso de algum medicamento
a) $\operatorname{Sim}$
b) Não

Se for SIM, indique qual: 


\section{Quantas porções desses alimentos você consome semanalmente:}

23. Soja e derivados:

24. Leguminosas (feijão, lentilha, grão de bico):

25. Oleaginosas(nozes, castanha do pará, amêndoa...):

26. Alimentos integrais:

27. Alimentos refinados (Arroz branco, pão branco, macarrão branco, etc.):

28. Frutas:

29. Ovo:

30. Leite e derivados: 
Diário Alimentar - dia da semana

\begin{tabular}{|c|l|l|}
\hline Refeição & Alimentos & Quantidade \\
\hline Desjejum & & \\
\hline Colação & & \\
\hline Almoço & & \\
& & \\
\hline Lanche & & \\
\hline Jantar & & \\
& & \\
\hline
\end{tabular}

Fracionamento diário: 
Diário Alimentar - dia da semana

\begin{tabular}{|c|l|l|}
\hline Refeição & Alimentos & Quantidade \\
\hline Desjejum & & \\
\hline Colação & & \\
\hline Almoço & & \\
& & \\
\hline Lanche & & \\
\hline Jantar & & \\
& & \\
\hline
\end{tabular}

Fracionamento diário: 
Diário Alimentar - final de semana

\begin{tabular}{|c|c|c|}
\hline Refeição & Alimentos & Quantidade \\
\hline Desjejum & & \\
\hline Colação & & \\
\hline Almoço & & \\
& & \\
\hline Lanche & & \\
\hline Jantar & & \\
& & \\
\hline
\end{tabular}

Fracionamento diário: 
HOSPITAL DAS CLÍNICAS

Anexo D

DA

FACULDADE DE MEDICINA DA UNIVERSIDADE DE SÃO PAULO

TERMO DE CONSENTIMENTO LIVRE E ESCLARECIDO

(Instruções para preenchimento no verso)

\section{I - DADOS DE IDENTIFICAÇÃO DO SUJEITO DA PESQUISA OU RESPONSÁVEL LEGAL}

1. NOME DO PACIENTE .

DOCUMENTO DE IDENTIDADE № : SEXO :.$M \square \quad F \square$

DATA NASCIMENTO: .......................

ENDEREÇO

BAIRRO:

2.RESPONSÁVEL LEGAL

APTO:

NATUREZA(grau de parentesco, tutor, curador etc.)

DOCUMENTO DE IDENTIDADE : SEXO: $\mathrm{M} \square \mathrm{F}$

DATA NASCIMENTO.: ....../.............

ENDEREÇO:

BAIRRO:

CEP: CIDADE: № APTO: TELEFONE: DDD ( ..............

\section{II - DADOS SOBRE A PESQUISA CIENTÍFICA}

1. TÍTULO DO PROTOCOLO DE PESQUISA Efeitos da dieta vegetariana no metabolismo de quilomícrons e aspectos qualitativos da HDL

PESQUISADOR: Juliana Christiano de Matos Vinagre

CARGO/FUNÇÃO: . Nutricionista INSCRIÇÃO CONSELHO REGIONAL № CRN 19124

UNIDADE DO HCFMUSP: ..... InCor - Laboratório de Metabolismo de Lípides

3. AVALIAÇÃO DO RISCO DA PESQUISA:

SEM RISCO

RISCO MÍNIMO $\mathbf{x}$

RISCO MÉDIO

RISCO BAIXO

RISCO MAIOR

(probabilidade de que o indivíduo sofra algum dano como consequência imediata ou tardia do estudo)

4.DURAÇÃO DA PESQUISA : 4 anos 


\section{III - REGISTRO DAS EXPLICAÇÕES DO PESQUISADOR AO PACIENTE OU SEU REPRESENTANTE LEGAL SOBRE A PESQUISA, CONSIGNANDO:}

1. justificativa e os objetivos da pesquisa ; 2. procedimentos que serão utilizados e propósitos, incluindo a identificação dos procedimentos que são experimentais; 3 . desconfortos e riscos esperados; 4 . benefícios que poderão ser obtidos; 5 . procedimentos alternativos que possam ser vantajosos para o indivíduo.

O colesterol "ruim" e a gordura da alimentação podem colaborar para termos de doenças do coração. Se ficarem muito tempo no nosso sangue podem formar placas de gordura nos vasos sanguíneos. Essas placas dificultam a chegada do oxigênio com o sangue no coração ou no cérebro. Quando isto acontece, a parte do coração que fica sem receber oxigênio, necrosa, acontecendo o infarto no miocárdio. Se isso acontecer no cérebro, ocorre o acidente vascular cerebral, ou como é conhecido, o derrame cerebral. Além disso, "o colesterol bom" tem que estar alto no sangue exercendo direito suas funções de proteção contra a formação das placas de gordura.

Com este estudo queremos avaliar se a dieta vegetaiana traz benefícios no metabolismo da gordura da alimentação, do colesterol ruim e do colesterol bom. Para isso, primeiramente vamos tirar uma amostra de $10 \mathrm{ml}$ de sangue para vários exames relacionados com gordura no sangue. Depois na mesma veia será feita uma injeção da mesma substância parecida com a gordura da dieta, numa quantidade tão pequena, que não consegue ser detectada no sangue. Por isso, ela possue uma pequena radioatividade, para que possamos medir sua presença no sangue. Essa radioatividade é muito baixa, 10 vezes menr que de um raio- $X$ de tórax. Depois da injeção, durante 1 hora, serão tirada 8 amostras de sangue de $5 \mathrm{ml}$ de sangue cada, por uma veia que vamos deixar pega, para não precisar picar todas as vezes. Depois, pela mesma veia será injetada uma quantidade muito pequena de outra substância, heparina (cerca de $70 \mu$ l) e colhida uma amostra de sangue de $10 \mathrm{ml}$, para testar se a gordura no seu sangue esta sendo quebrada normalmente. Para esses exames você ficará no laboratório durante cerca de 1 hora e meia.

Irão participar desse estudo, pessoas vegetarianas veganas (que não comem nenhum tipo de alimento de origem animal), lacto-ovo vegetarianas (não comem carne) e não vegetarianas e os resultados dos exames serão comparados entre esse três grupos. Você terá acesso a todos os resultados, assim como as explicações sobre eles. 
Quanto aos desconfortos relacionados a esse exames, existe o fato de você ter que permanecer no laboratório durante o tempo citado acima para cada exame e as picadas nas veias para as injeções e coletas de sangue. Os exames não causam nenhum desconforto ruim à saúde e tem o importante objetivo de mostrar se a dieta vegetariana tem efeitos benéficos em fatores de risco muito importantes de doenças cardiovasculares, a gordura da alimentação, "o colesterol ruim" e "o colesterol bom'

\section{IV - ESCLARECIMENTOS DADOS PELO PESQUISADOR SOBRE GARANTIAS DO SUJEITO DA PESQUISA:}

1. acesso, a qualquer tempo, às informações sobre procedimentos, riscos e benefícios relacionados à pesquisa, inclusive para dirimir eventuais dúvidas.

2. liberdade de retirar seu consentimento a qualquer momento e de deixar de participar do estudo, sem que isto traga prejuízo à continuidade da assistência.

3. salvaguarda da confidencialidade, sigilo e privacidade.

4. disponibilidade de assistência no HCFMUSP, por eventuais danos à saúde, decorrentes da pesquisa.

5. viabilidade de indenização por eventuais danos à saúde decorrentes da pesquisa.

\section{INFORMACCÕES DE NOMES, ENDERECCOS E TELEFONES DOS RESPONSÁVEIS PELO ACOMPANHAMENTO DA PESQUISA, PARA CONTATO EM CASO DE INTERCORRÊNCIAS CLÍNICAS E REAÇÕES ADVERSAS.}

Prof Dr. Raul Cavalcante Maranhã: InCor - Av. Dr. Éneas de Carvalho Aguiar, 44 - Laboratório de Metabolismo de Lípides - 1ํㅗㄴobsolo/ Bloco 2 Tel: 3069-5108 / 3069-5574

Juliana Christiano de Matos Vinagre: Rua Dr. Augusto de Miranda, 1071 casa 5 - Pompéia - São Paulo - SP - Tel: 25890496 / 71517372 


\section{VII - CONSENTIMENTO PÓS-ESCLARECIDO}

Declaro que, após convenientemente esclarecido pelo pesquisador e ter entendido o que me foi explicado, consinto em participar do presente Protocolo de Pesquisa
São Paulo,
de
de 20

assinatura do sujeito da pesquisa ou responsável legal

\section{INSTRUÇÕES PARA PREENCHIMENTO}

\section{(Resolução Conselho Nacional de Saúde 196, de 10 outubro 1996)}

1. Este termo conterá o registro das informações que o pesquisador fornecerá ao sujeito da pesquisa, em linguagem clara e accessível, evitando-se vocábulos técnicos não compatíveis com o grau de conhecimento do interlocutor.

2. A avaliação do grau de risco deve ser minuciosa, levando em conta qualquer possibilidade de intervenção e de dano à integridade física do sujeito da pesquisa.

3. O formulário poderá ser preenchido em letra de forma legível, datilografia ou meios eletrônicos.

4. Este termo deverá ser elaborado em duas vias, ficando uma via em poder do paciente ou seu representante legal e outra deverá ser juntada ao prontuário do paciente.

5. A via do Termo de Consentimento Pós-Informação submetida à análise da Comissão de Ética para Análise de Projetos de Pesquisa -CAPPesq deverá ser idêntica àquela que será fornecida ao sujeito da pesquisa. 